\title{
Numerical and experimental investigation of hydrodynamics and light transfer in open raceway ponds at various algal cell concentrations and medium depths
}

\author{
Hossein Amini ${ }^{\mathrm{a}, *}$, Abolhasan Hashemisohi ${ }^{\mathrm{a}}$, Lijun Wang ${ }^{\mathrm{b}, * *}$, Abolghasem \\ Shahbazi $^{\mathrm{b}}$, Marwan Bikdash ${ }^{\mathrm{a}}$, Dukka KC ${ }^{\mathrm{a}}$, Wenqiao Yuan ${ }^{\mathrm{c}}$ \\ ${ }^{a}$ Computational Science and Engineering Department, NC A\&T State University; 1601 \\ E. Market St. Greensboro, NC 27411 \\ ${ }^{b}$ Chemical, Biological and Bioengineering Department NC A\&T State University 1601 E. \\ Market Street Greensboro, NC 27411 \\ ${ }^{c}$ Biological and Agricultural Engineering Department NC State University D.S Weaver \\ Labs, Campus Box 7625, Raleigh, NC 27695
}

\section{Abstract}

A spectral radiation-transport model was integrated with a three dimensional computational fluid dynamics model to simulate the hydrodynamics and light transfer in open raceway ponds (ORPs). The predicted threedimensional velocity and light intensity agreed well with measured values collected on a lab-scale ORP. However, there was a slight difference in the predicted velocity profiles using two different types of boundaries for the paddlewheel, i.e., the moving zone boundary and inlet velocity boundary, with $R^{2}$ values between the predicted and measured velocities of 0.9947 and

\footnotetext{
*E-mail address: hossein.amini.che@gmail.com

** corresponding author; E-mail address: lwang@ncat.edu
} 
0.9838 , respectively. The $R^{2}$ value between the predicted and measured light intensity was 0.9939 . Simulations were further conducted on a large-scale ORP with $100 \mathrm{~m}^{2}$ surface area operated at total medium depths of 0.2 and $0.3 \mathrm{~m}$, average cell concentration of $0.4 \mathrm{~g} / \mathrm{L}$, and inlet velocities of $0.1,0.2$ and $0.3 \mathrm{~m} / \mathrm{s}$ from the paddlewheel. The increase of inlet flow velocity from 0.1 to $0.2 \mathrm{~m} / \mathrm{s}$ resulted in a more uniform cell concentration profile. However, when the inlet velocity was further increased from 0.2 to $0.3 \mathrm{~m} / \mathrm{s}$, there was only a slight increase in the uniformity of the cell concentration. In addition, the simulation results showed that sedimentation of cells more likely occurred at the bottom of the ORP with a total medium depth of $0.2 \mathrm{~m}$ than at $0.3 \mathrm{~m}$ at the same inlet velocity. The increase of inlet velocity from the paddlewheel resulted in a uniformly distributed light intensity in the region near the medium surface (e.g., $0.05 \mathrm{~m}$ depth from the surface) owing to improved mixing. However, owing to a sudden drop in the light intensity after a few centimeters from the medium surface, the cell sedimentation that occurred at the bottom of the ORPs had negligible effects on the light penetration depth in the medium.

Keywords: Open raceway pond; microalgae; light intensity distribution; computational fluid dynamics; Chlorella vulgaris 


\section{1. Introduction}

2 Microalgae have been considered as energy crops for biofuels since the $31970 \mathrm{~s}[1,2]$. Open raceway ponds (ORPs) are considered as economical sys4 tems for large-scale cultivation of microalgae [3]. It is critical and challenging 5 to achieve a uniform distribution of nutrients, $\mathrm{CO}_{2}$, light, and algal cells in 6 an ORP for high productivity and energy efficiency [4]. The cultivation of 7 microalgae in an ORP is a complicated hydrodynamic process in multiphase 8 flow involving solid algal cells, $\mathrm{CO}_{2}$ and $\mathrm{O}_{2}$ gases, and liquid culture medium. 9 Proper mixing during the multiphase flow in an ORP is the key to efficiently

supply $\mathrm{CO}_{2}$, remove generated $\mathrm{O}_{2}$, evenly distribute nutrients, prevent cell sedimentation, and improve the accessibility of light for all cells [4-6].

Light is one of the important factors that affect the microalgae growth rate [7]. The density of algal culture affects both the local light intensity and light penetration depth [7]. In order to achieve optimal design and scale-up of an ORP, it is very important to understand the effects of design parameters and operating conditions on mixing and light distribution patterns in an ORP. The effects of different ORP geometries and designs on mixing and light intensity distribution have been studied experimentally $[3,5,8]$. The velocity distribution in an ORP can be used to determine the effectiveness of mixing 
in ORP channels. However, it cannot fully predict the algal cell distribution that directly affects the light distribution in the ORP [4]. Therefore, it is important to study the algal cell flow patterns in an ORP and the effect of lighting characteristics such as light scattering and absorption coefficients on algal cells.

The simulation of radiative transport within a photobioreactor is computationally challenging owing to its spatial, directional, and wavelength dependencies resulting from the complex interactions of radiation with water, algae, and air. However, modern commercial computational fluid dynamics (CFD) tools enable us to make use of a wavelength dependent radiative transfer equation (RTE) in well-resolved complex geometries of algal culturing systems [9]. CFD models can be used to predict the multiphase flow patterns and light intensity distribution in an $\operatorname{ORP}[8,10,11]$. In addition, they were used to evaluate the power consumption, dead zone volume, and shear stress under different velocities, channel length-to-width ratios, and culture depths [12-14]. Furthermore, CFD models were used to study cell trajectory and mixing efficiency in ORPs $[3,4]$. It is also possible to apply CFD simulations to analyze the radiation characteristics of solids in suspension, and the effects of solid concentration and system geometry on the light 
transfer pattern $[7,15,16]$. However, the mixing characteristics in those published CFD models were evaluated solely based on the fluid flow pattern in ORPs without consideration of real algal cells. Those models could not predict the dynamic algal distribution in ORPs, which affects light distribution and mixing.

The objective of this study was to develop a CFD model to simulate the hydrodynamics of multiphase flow and the resulting light intensity distribution in an ORP simultaneously with microalgal cells at various medium depths. The CFD model was further validated by the experimental data of velocity and light distribution collected from a lab-scale ORP.

\section{Materials and experimental methods}

\subsection{Microalgae strain and culture medium}

C. vulgaris (UTEX 2714) was purchased from the UTEX culture collection of algae at the University of Texas in Austin. The algal seed was cultivated using the autoclaved Bolds medium. The seed tubes were incubated in a shaker (AlgaeTron AG 130-ECO, Quibit systems Inc., Canada) at a temperature of $24^{\circ} \mathrm{C}$ and light intensity of $22 \mathrm{~W} / \mathrm{m}^{2}$ to prepare the preculture as recommended by the supplier. 
The traditional Bold's medium was used to cultivate $C$. vulgaris in the ORP. The Bold's medium was composed of $25 \mathrm{mg} / \mathrm{L} \mathrm{CaCl} 2 \cdot 2 \mathrm{H}_{2} \mathrm{O}, 75 \mathrm{mg} / \mathrm{L}$ $\mathrm{MgSO}_{4} \cdot 7 \mathrm{H}_{2} \mathrm{O}, 250 \mathrm{mg} / \mathrm{L} \mathrm{NaNO}_{3}, 25 \mathrm{mg} / \mathrm{L} \mathrm{NaCl}, 75 \mathrm{mg} / \mathrm{L} \mathrm{K}_{2} \mathrm{HPO}_{4}, 175 \mathrm{mg} / \mathrm{L}$ $\mathrm{KH}_{2} \mathrm{PO}_{4}, 8.82 \mathrm{mg} / \mathrm{L} \mathrm{ZnSO}_{4} .7 \mathrm{H}_{2} \mathrm{O}, 1.44 \mathrm{mg} / \mathrm{L} \mathrm{MnCL}_{2} .4 \mathrm{H}_{2} \mathrm{O}, 0.71 \mathrm{mg} / \mathrm{L} \mathrm{MoO}_{3}$, $1.57 \mathrm{mg} / \mathrm{L} \mathrm{CuSO}_{4} .5 \mathrm{H}_{2} \mathrm{O}, 0.49 \mathrm{mg} / \mathrm{L} \mathrm{Co}\left(\mathrm{NO}_{3}\right)_{2} .6 \mathrm{H}_{2} \mathrm{O}, 11.42 \mathrm{mg} / \mathrm{L} \mathrm{H}_{3} \mathrm{BO}_{3}, 50.0$ $\mathrm{mg} / \mathrm{L} \mathrm{EDTA}, 31.0 \mathrm{mg} / \mathrm{L} \mathrm{KOH}, 4.98 \mathrm{mg} / \mathrm{L} \mathrm{FeSO} 4.7 \mathrm{H}_{2} \mathrm{O}$ and $1.0 \mathrm{ml} / \mathrm{L} \mathrm{H}_{2} \mathrm{SO}_{4}$.

\subsection{Cultivation of C. vulgaris in lab-scale ORP}

Experiments were carried out in a lab-scale ORP in a greenhouse as shown in Figure 1 to validate the CFD model. The ORP was constructed of fiber glass, with dimensions of $1.4 \mathrm{~m}$ length $\times 0.5 \mathrm{~m}$ depth $\times 0.35 \mathrm{~m}$ width. The paddle wheel was constructed of stainless steel, including five blades with a length of $0.30 \mathrm{~m}$ and a width of $0.24 \mathrm{~m}$. The paddle wheel was driven by a two-phase motor with variable speed to control the rotational speed of the impeller. The paddle wheel rotational speed was set at $10 \mathrm{rpm}$ for all experiments. The minimum gap between the tip of the blades and the pond bottom was $0.01 \mathrm{~m}$. Experiments were conducted under a medium depth of $0.2 \mathrm{~m}$ and a total medium volume of $140 \mathrm{~L}$. Fluorescent light panels, each of which includes eight fluorescent light bulbs with a total power of $97 \mathrm{~W}$, were installed directly above the paddle wheel of the ORP to achieve a constant 


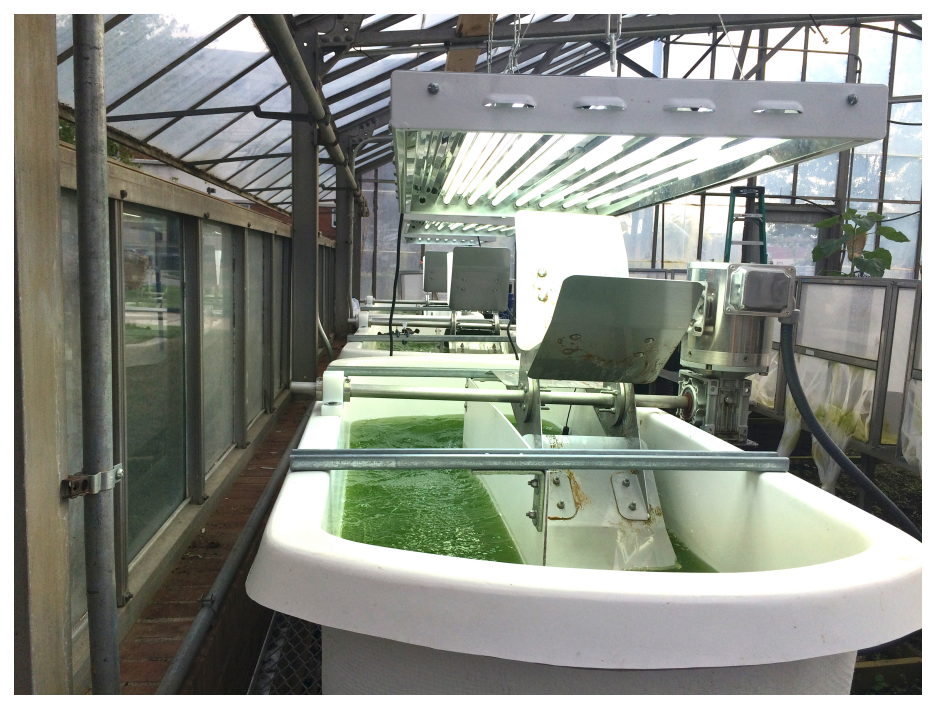

(a) Experimental ORP

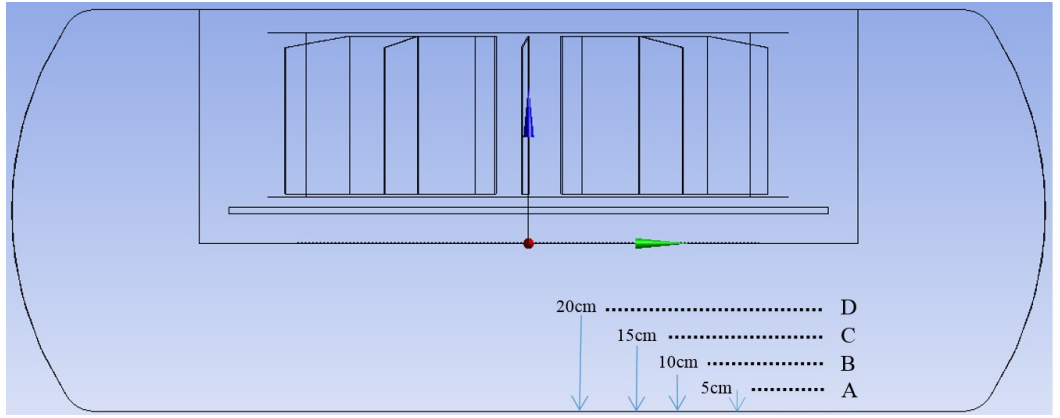

(b) Locations for velocity measurement

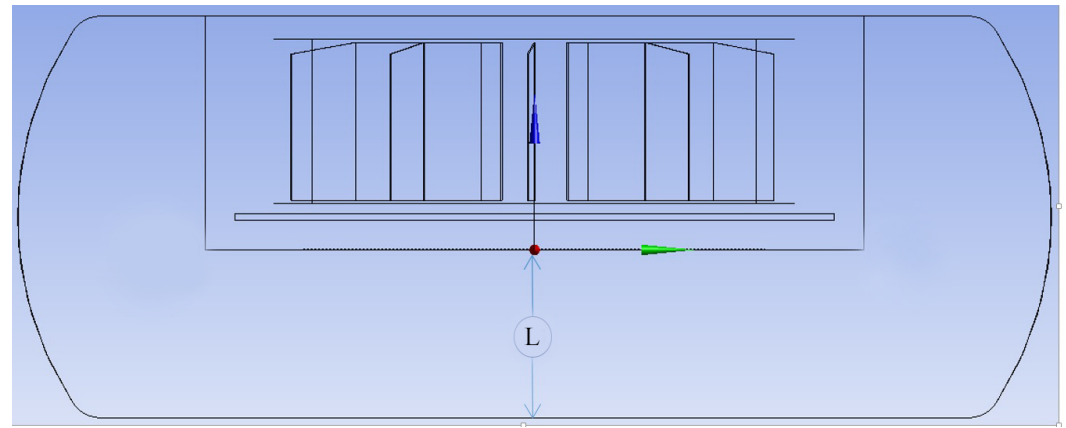

(c) Locations for light intensity measurement

Figure 1: Lab-scale ORP in a greenhouse and the diagram of the locations for the measurement of velocity and light intensity 
continuous light intensity of $22 \mathrm{~W} / \mathrm{m}^{2}$ on the surface of the pond.

A total of $140 \mathrm{~L}$ precultured $C$. vulgaris in Bolds medium at a cell concentration of $0.1 \mathrm{~g} / \mathrm{L}$ was prepared and transferred into each ORP at the beginning of the cultivation.

\subsection{Velocity and light intensity measurements in ORP channels}

The three-dimensional velocity distribution $\left(v_{x}, v_{y}\right.$, and $\left.v_{z}\right)$ in the ORP was measured at an acoustical sampling frequency of $25 \mathrm{~Hz}$ by an acoustic Doppler velocimeter (ADV, NorTek, Vectrino, Norway). The lab-scale ORP has two channels separated by a divider as shown in Figure 1. The paddlewheel is located in one channel. The field velocity measurements were carried out at 12 locations immediately after the bend of the other channel with three different depths of $0.05,0.1$, and $0.15 \mathrm{~m}$ and four different distances of $0.05,0.1,0.15$, and $0.2 \mathrm{~m}$ from the channel wall, as shown in Figure $1 b$.

Various concentrations of $C$. vulgaris at $0.1,0.2,0.3$, and $0.4 \mathrm{~g} / \mathrm{L}$ were used in the ORP illuminated by the panels to measure the light distribution. The photosynthetically active radiation (PAR) under the water surface was measured at various depths $(0-0.1 \mathrm{~m})$ inside the ORP at the center of the channel without the paddle wheel as shown in Figure 1c, using an under- 
${ }_{111}=3 \mu \mathrm{m}[18]$ and $\rho=1125 \mathrm{~kg} / \mathrm{m}^{3}$ calculated from wet cell mass and volume) Nebraska, USA), connected to a data logger (LI1400, Li-cor Inc., Nebraska, USA). This quantum sensor measures the PAR in the wavelength range of 400-700 nm from all angles in one hemisphere.

\section{Mathematical modeling of multiphase flow and light transfer}

\subsection{Eulerian multiphase CFD model}

An Eulerian multiphase model was developed to simulate the fluid dynamics of algal cells and culture medium. The two phases of algal cells and culture medium were treated mathematically as fully interpenetrating continua by introducing the concepts of solid-phase viscosity and solid-phase pressure for algal cells [17]. The fluid of the culturing medium was considered as the primary phase. The solid algal cells were considered as the secondary phase to be dispersed in the first phase. A volumetric fraction, $\alpha$, which varies from 0 to 1 , was assigned to each physical phase. Various volumetric fractions were used in the model to represent different algal cell concentrations. C. vulgaris, which has a spherical shape and single cell structure $\left(d_{p}\right.$ was used as the model algae in the culture medium.

water light sensor (Li-cor LI-192 Underwater Quantum Sensor, Li-cor Inc., 
The mass conservation equation for the phase, $q$, which is either for the algal cells or the culture medium, is given by

$$
\frac{\partial}{\partial t}\left(\alpha_{q} \rho_{q}\right)+\nabla \cdot\left(\alpha_{q} \rho_{q} \vec{u}_{q}\right)=\sum_{p=1}^{n}\left(\dot{m}_{p q}-\dot{m}_{q p}\right)
$$

where $\alpha_{q}$ is the volumetric fraction of the phase, $\rho_{q}$ is the density of the phase $q, \vec{u}_{q}$ is the velocity vector of the phase $q$, and $\dot{m}_{p q}$ and $\dot{m}_{q p}$ are the interphase mass transfer between the $p^{\text {th }}$ and $q^{\text {th }}$ phase, respectively. The total volumetric fraction, which is the sum of all volumetric fractions, must be equal to unity, i.e., $\sum_{q=1}^{n} \alpha_{q}=1$ in each computational cell. The momentum conservation equation for the phase, $q$, is given by

$$
\begin{aligned}
\frac{\partial}{\partial t}\left(\alpha_{q} \rho_{q} \vec{u}_{q}\right)+\nabla \cdot\left(\alpha_{q} \rho_{q} \vec{u}_{q} \vec{u}_{q}\right)= & -\alpha_{q} \nabla p_{q}+\nabla \cdot \overline{\bar{\tau}}_{q} \\
& +\alpha_{q} \rho_{q}\left(\vec{F}_{e x, q}+\vec{F}_{l i f t, q}+\vec{F}_{v m, q}\right) \\
& +\sum_{p=1}^{n}\left(\vec{R}_{p q}+\dot{m}_{p q} \vec{u}_{q p}-\dot{m}_{q p} \vec{u}_{q p}\right)
\end{aligned}
$$

where $\vec{F}_{e x, q}, \vec{F}_{l i f t, q}$, and $\vec{F}_{v m, q}$ are the external body force, lift force, and virtual mass force, respectively. As the lift force is usually insignificant compared to the drag force, $\vec{F}_{\text {lift,q }}$ is assumed to be negligible [17]. $\vec{u}_{q p}$ and $\vec{u}_{p q}$ 
${ }_{129}$ are the interphase velocities, and $\vec{R}_{p q}$ is the drag force between phases. $\overline{\bar{\tau}}_{q}$ 130 stands for the stress-strain tensor of the $q^{\text {th }}$ phase that is defined as

${ }_{131} \overline{\bar{\tau}}_{q}=\alpha_{q} \mu_{q}\left(\nabla \vec{u}_{q}+\nabla \vec{u}_{q}^{T}\right)+\alpha_{q}\left(\lambda_{q}-\frac{2}{3} \mu_{q}\right) \nabla \cdot \vec{u}_{q} \overline{\bar{I}}$

132 133

134

142

where $\mu_{q}$ and $\lambda_{q}$ are the bulk viscosity and shear of the phase, $q$, respectively, and $\overline{\bar{I}}$ is the unit tensor.

\subsubsection{Fluid-solid momentum exchange}

The drag force acting on a single particle in a solid particle system can be expressed by the product of a liquid-solid momentum exchange coefficient $K_{s l}$ and the relative (or slip) velocity between the liquid and solid phases $[17]$

$$
\vec{R}_{l s}=K_{l s}\left(\vec{u}_{l}-\vec{u}_{s}\right)
$$

The fluid-solid exchange coefficient for a dilute solid-liquid system, such as a microalgal culture medium, can be written as [17]

$$
K_{s l}=\frac{3}{4} C_{D} \frac{\alpha_{s} \alpha_{l} \rho_{l}\left|\vec{u}_{s}-\vec{u}_{g}\right|}{d_{s}} \alpha_{l}^{-2.65}
$$


143

144

154

155

157

154

55

where $C_{D}$ is given by

$$
C_{D}=\frac{24}{\alpha_{l} R e_{s}}\left[1+0.15\left(\alpha_{l} R e_{s}\right)^{0.687}\right]
$$

\subsubsection{Turbulence model}

The RNG $k-\varepsilon$ turbulence model with a time-dependent solver was used to simulate the fluid flow in the coupled paddlewheel and raceway pond.

The RNG $k-\varepsilon$ can achieve stable calculations even at a high Reynolds number. In addition, the $k-\varepsilon$ turbulence model generates solutions for complex geometries owing to the implementation of a wall function [4]. The governing equations of the turbulent kinetic energy, $k$, and dissipation rate, $\varepsilon$, are given by

$$
\rho \frac{\partial k}{\partial t}+\rho u_{j} \frac{\partial k}{\partial x_{j}}=\tau_{i j} \frac{\partial u_{i}}{\partial x_{j}}+\frac{\partial}{\partial x_{j}}\left[\left(\mu+\frac{\mu_{t}}{\sigma_{k}}\right) \frac{\partial k}{\partial x_{j}}\right]-\rho \varepsilon
$$

$+C_{\varepsilon 1} \frac{\varepsilon}{k} \tau_{i j} \frac{\partial u_{i}}{\partial x_{j}}-C_{\varepsilon 2} \rho \frac{\varepsilon^{2}}{k}$ 
where $\sigma_{k}$ and $\sigma_{\varepsilon}$ are the turbulent Prandtl numbers for the kinetic energy and dissipation rate, respectively, while $C_{\varepsilon 1}$ and $C_{\varepsilon 2}$ are the first and second experimental model constants for dissipation rate, respectively. The values assigned were $\sigma_{k}=1.0, \sigma_{\varepsilon}=1.3, C_{\varepsilon 1}=1.44, C_{\varepsilon 2}=1.92$, and $C_{\mu}=0.09$.

The turbulent viscosity defined by the $k-\varepsilon$ turbulence model is given by

$$
\mu_{t}=\frac{\rho C_{\mu} k^{2}}{\varepsilon}
$$

\subsection{Modeling of light transfer}

\subsubsection{Light transfer governing equation}

Radiative intensity in an ORP depends on the spatial position and angular direction. Radiation transfer into an absorbing, scattering, and nonemitting medium, such as algal suspensions in a culture medium, is governed by the RTE, which is derived from energy balance. In ANSYS Fluent, light transfer in the culture medium can be modeled by the discrete ordinates (DO) radiation model, which is based on the RTE [19]. The basic RTE at 
172

173

174

175

176

position $\vec{r}$ and in the direction $\vec{s}$ can be written as

$$
\begin{aligned}
\frac{d I(\vec{r}, \vec{s})}{d s} & +\left(k+\sigma_{s}\right) I(\vec{r}, \vec{s}) \\
& =k n^{2} \frac{\sigma T^{4}}{\pi}+\frac{\sigma_{s}}{4 \pi} \int_{0}^{4 \pi} I\left(\vec{r}, \vec{s}^{\prime}\right) \Phi\left(\vec{s} \cdot \vec{s}^{\prime}\right) d \Omega^{\prime}
\end{aligned}
$$

where $\vec{r}$ is the position vector, $\vec{s}$ is the direction vector, $\vec{s}^{\prime}$ is the scattering direction vector, $s$ is the path length, $k$ is the absorption coefficient, $n$ is the refractive index, $\sigma_{s}$ is the scattering coefficient, $\sigma$ is the Stefan-Boltzmann constant $\left(5.67 \times 10^{-8} \mathrm{~W} / \mathrm{m}^{2} \cdot \mathrm{K}^{4}\right), I$ is the radiation intensity (which depends on $\vec{r}$ and $\vec{s}$ ), $T$ is the local temperature, $\Phi$ is the phase function, and $\Omega^{\prime}$ is the solid angle. The phase function $\Phi\left(\vec{s} \cdot \vec{s}^{\prime}\right)$ accounts for scattering from direction $\vec{s}^{\prime}$, to direction $\vec{s}$, and determines the fraction of in-scattering radiation.

Several computational methods for solving equation (10) have been established. However, only the DO finite volume and Monte Carlo (MC) methods can be used to model non-gray radiation and semi-transparent walls [20]. The MC method is not often used in a CFD context owing to its high computational cost, as it is difficult to couple MC radiation calculations with a fluid dynamics solver. Consequently, the DO method was used to solve the 
RTE in this study.

\subsubsection{Medium optical properties}

The absorption, scattering, and extinction coefficients in Equation (10) are strongly dependent on the wavelength [19]. Under a single scattering regime, the radiation characteristics of microorganisms are linearly dependent on their concentration [19]. The specific scattering, absorption, and extinction coefficients of $C$. vulgaris at $3.5 \mathrm{~g} / \mathrm{L}$ were taken from literature [21] and shown in Figure 2.

The average optical characteristics of $C$. vulgaris medium in the visible light range $(400-700 \mathrm{~nm})$ were used to calculate the light intensity. The optical characteristics of $C$. vulgaris at different local culture concentrations can be determined by [21]

$$
E_{\text {ext }, \lambda}=\frac{\beta_{\lambda}}{X} \quad, \quad A_{a b s, \lambda}=\frac{k_{\lambda}}{X} \quad, \quad S_{s c a t, \lambda}=\frac{\sigma_{\lambda}}{X}
$$

where $E_{e x t, \lambda}$ is the specific spectral extinction coefficient; $A_{a b s, \lambda}$ is the specific spectral absorption coefficient; $S_{s c a t, \lambda}$ is the specific spectral scattering coefficient; $\lambda$ refers to the wavelength, $\beta_{\lambda}$ is the spectral extinction coefficient, and $X$ is the cell concentration $\left(\mathrm{kg} / \mathrm{m}^{3}\right)$. To calculate the optical character- 


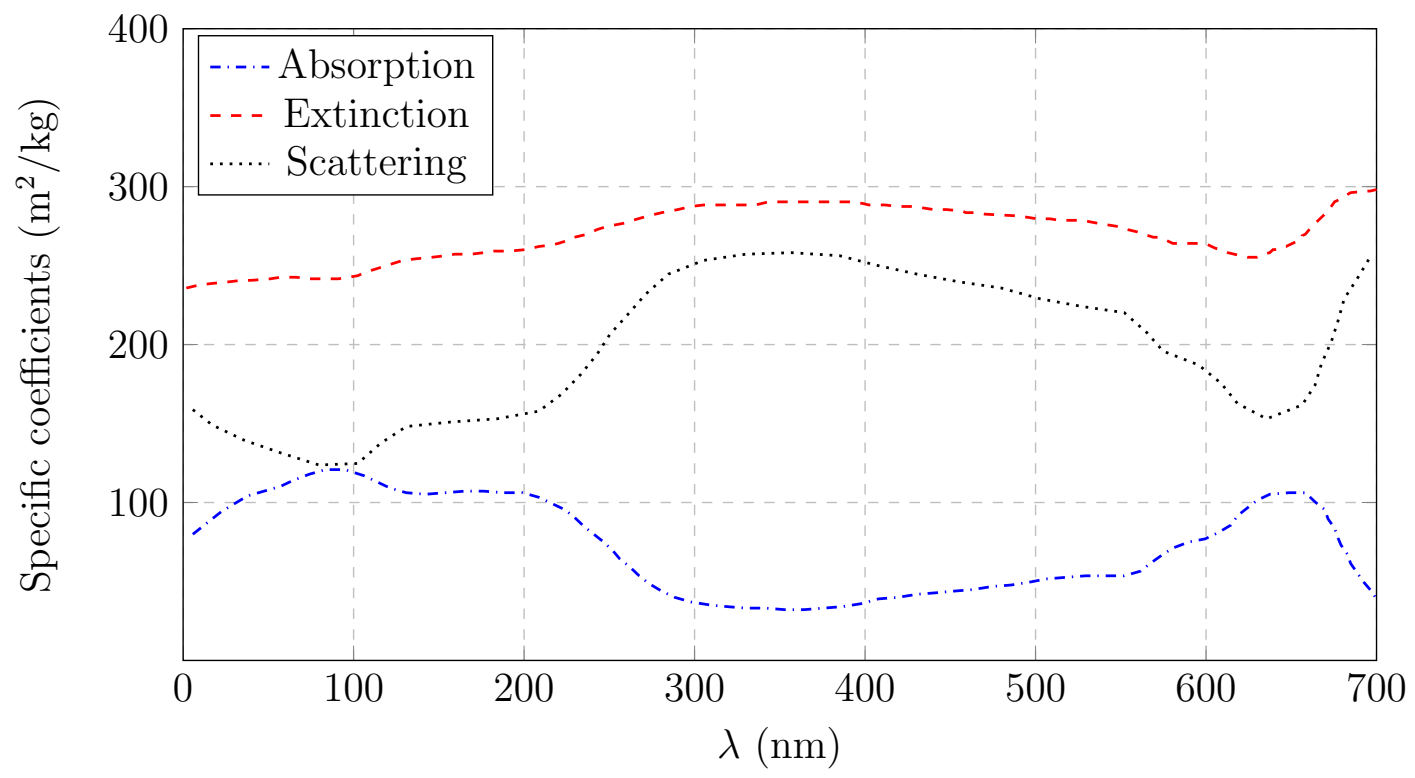

Figure 2: Spectral specific absorption $\left(A_{a b s, \lambda}\right)$, scattering $\left(S_{\text {scat }, \lambda}\right)$, and extinction $\left(E_{\text {ext }, \lambda}\right)$ coefficients of $C$. vulgaris at a culture concentration of $3.5 \mathrm{~g} / \mathrm{L}[21]$

istics of $C$. vulgaris at a particular cell concentration, the values presented in Figure 2 should be divided by 3.5 .

The scattering coefficient, $\sigma_{s}$, can be expressed as [19]

$$
\sigma_{s, \lambda}=\beta_{\lambda}-k_{\lambda}
$$

Figures 3a-3d show the specific optical characteristics of C. vulgaris, at various concentrations in the range of $0.1-0.4 \mathrm{~g} / \mathrm{L}$, which were calculated by Equations (11) and (12) using the data given in Figure 2. User defined functions (UDFs) were written in C programming language to determine the 


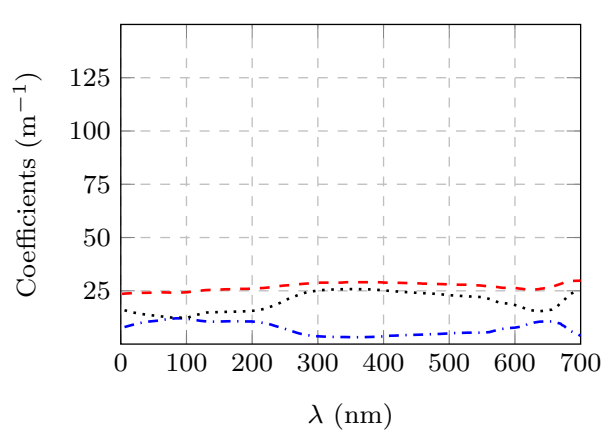

(a)

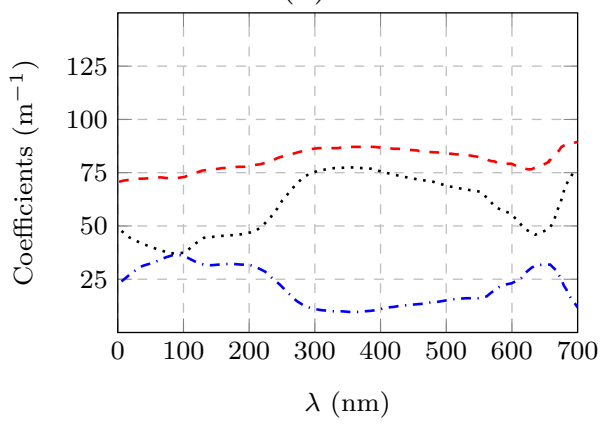

(c)

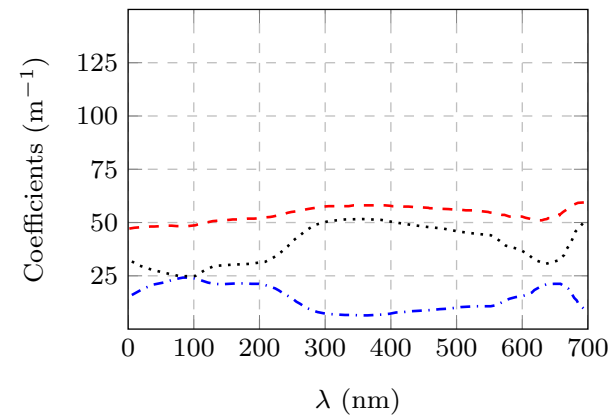

(b)

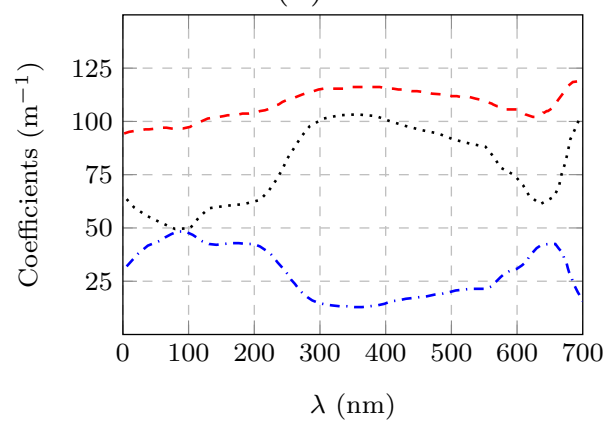

(d)

--.-- Absorption; - - - Extinction; ....... Scattering

Figure 3: Absorption $\left(k_{\lambda}\right)$, scattering $\left(\sigma_{\lambda}\right)$, and extinction $\left(\beta_{\lambda}\right)$ coefficients for $C$. vulgaris [21] at the concentrations of (a) $0.1 \mathrm{~g} / \mathrm{L}$, (b) $0.2 \mathrm{~g} / \mathrm{L}$, (c) $0.3 \mathrm{~g} / \mathrm{L}$, and (d) $0.4 \mathrm{~g} / \mathrm{L}$

213

optical properties of $C$. vulgaris at various local cell concentrations. The UDFs were then hooked to the absorption and scattering coefficients tab on the material panel of the ANSYS Fluent CFD simulation platform for the algal cell phase.

\subsection{Boundary conditions}

The wall boundary condition was used for the side walls and bottom of the pond. A symmetry boundary condition was assigned for the top of the 
system. There are two ways to define the boundary of the paddle wheel in the CFD model: (1) moving zone and (2) velocity inlet. The inclusion of the paddle wheel in the moving zone of a multiphase CFD model for simulating a large-scale ORP is computationally intensive [4]. It is common to simplify the model and reduce the computational time by using a constant momentum source of inlet velocity generated by the paddle wheel in CFD models [4, 10-12].

\subsubsection{Moving zone boundary of a paddle wheel}

For the simulation of the lab-scale ORP using the CFD model, the moving paddle wheel was considered as a moving cylindrical zone that passes against a cylindrical interface using the sliding mesh technique. The paddle wheel blades were considered as wall boundary conditions circulating the water in the channels. An interface boundary condition was used to connect the moving zone with the multiphase-fluid zone in the ORP.

\subsubsection{Inlet velocity boundary of paddle wheel}

For the simulation of the large-scale ORP, the inlet velocity boundary condition was used to account for the rotating paddlewheel. This simplification can significantly reduce the computational time [8]. To validate this 
simplification, simulations for the lab-scale ORP were conducted using both boundary conditions for the paddle wheel which were used during the experiments on the lab-scale ORP.

\subsubsection{Lighting boundary conditions}

The bottom and side walls of the ORP were considered to be opaque. The top wall was considered as a semi-transparent wall. The top wall was exposed to a radiation of $22 \mathrm{~W} / \mathrm{m}^{2}$ light intensity on the top of the fluid free surface used in the lab-scale ORP during experiments.

\subsection{Computer simulation procedure}

All simulations were conducted using the ANSYS Fluent parallel mode on a Dell Precision T7810 work station with 2 Intel Xeon CPUs and a total number of 16 cores (E5- 2687W v3, 3.10GHz), 64 GB of RAM, and Windows 7 operating system.

\subsubsection{Lab-scale ORP modeling and experimental validation} The predicted three-dimensional velocities $\left(v_{x}, v_{y}\right.$, and $\left.v_{z}\right)$ and light intensities were compared with those values measured at different locations of the lab-scale ORP indicated in Figures 1b and 1c. 


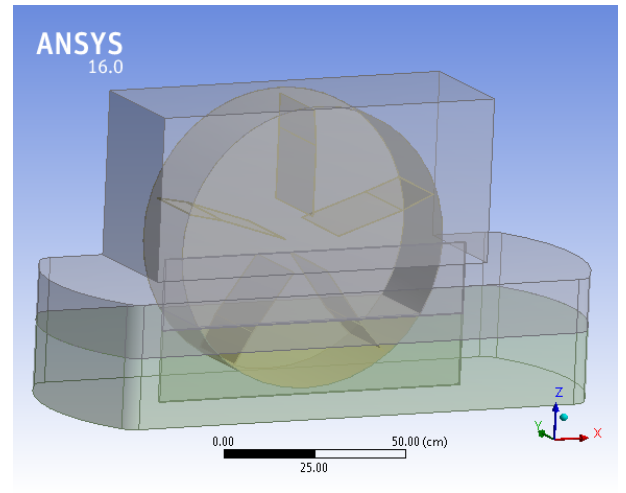

(a)

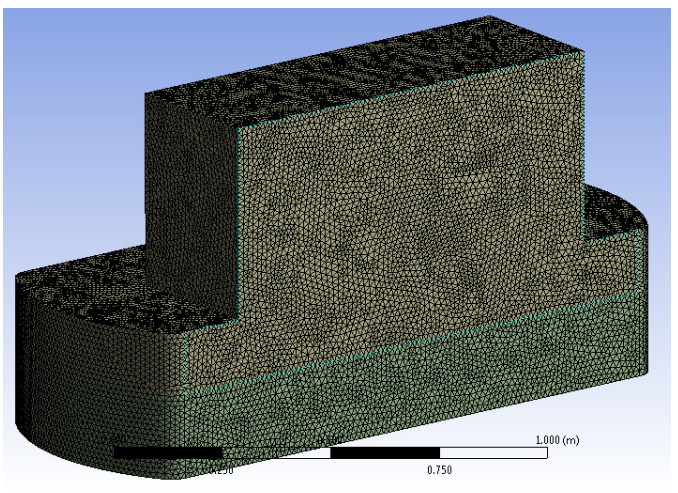

(b)

Figure 4: (a) Geometric design and (b) mesh generation of the CFD model

The three-dimensional geometric model was created in ANSYS workbench 16.0 using DesignModeler as depicted in Figure 4a. As the paddle wheel was not entirely submerged, the computational domain at the paddle wheel location was extended up to $0.8 \mathrm{~m}$ from the bottom of the ORP in order to encompass the impeller fully. Therefore, the ORP was divided into three domains: the moving zone of paddle wheel, multiphase culture medium zone, and air zone at the top of the culture medium.

The unstructured hexahedral mesh was created by the software ANSYS DesignMesh 16.0 (Figure 4b). The sliding mesh technique was used to account for the paddle wheel rotation. This method represents the movement of the entire paddle wheel. The optimum mesh size was found to be $0.014 \mathrm{~m}$, where the results did not significantly change by further decreasing the mesh 
size. This mesh size led to $1.02 \times 10^{6}$ CFD cells. Time step sizes larger than $0.01 \mathrm{~s}$ resulted in divergence, whearas very small time step sizes were also computationally intense. Therefore, to prevent a diverging solution and save computational time, the time step size was set at $0.01 \mathrm{~s}$.

To replace the moving zone boundary of the paddle wheel with the velocity inlet boundary condition, the linear velocity was calculated from the angular velocity of the rotating paddle wheel by

$$
v=r \omega
$$

where $v$ is the linear velocity $(\mathrm{m} / \mathrm{s}), r$ is the radius of the paddle wheel $(\mathrm{m})$, and $\omega$ is the angular velocity of the rotating paddle wheel ( $\mathrm{rad} / \mathrm{s})$.

\subsubsection{Simulation of scaled-up ORPs}

The model was used to study the effects of the inlet velocity from a rotating paddle wheel and channel depth on algal cell and light distribution in a large-scale ORP. The ORP had an area of $100 \mathrm{~m}^{2}$ with an aspect ratio (AR) of channel length to width of 10 , and two different medium depths of 0.2 and $0.3 \mathrm{~m}$.

A case study was conducted to predict the light distribution in the chan- 
nels of ORPs for the weather condition in North Carolina, USA. The solar irradiance data provided by NREL, represents the light intensity on the surface of the medium. The maximum solar irradiance of $330 \mathrm{~W} / \mathrm{m}^{2}$ in June was used as the top radiation boundary condition of the CFD model.

\subsubsection{Determination of pseudo-steady-state condition}

As the fluid flow in an ORP is a transient phenomenon, simulations started with zero velocity as the initial condition. However, a pseudo-steadystate condition can be defined in which there are no significant changes in the maximum velocity and the velocity profile when the simulation time further increases. The simulation time required to achieve the pseudo-steady state was defined as the minimum required mixing time. After the pseudo-steady state was reached, the predicted three-dimensional velocities at each measuring location for the next $20 \mathrm{~s}$ simulation time at intervals of $0.25 \mathrm{~s}$ were exported to an excel file to calculate the average velocities in the $x, y$, and $z$ directions and were compared to the experimental data measured with the ADV instrument. 


\section{Results and discussion}

\subsection{CFD code validation}

Figure 5 shows the predicted velocity profile distribution in the lab-scale ORP at a distance of $5 \mathrm{~cm}$ from the medium surface at various flow times. When the rotational speed of the paddle wheel was $10 \mathrm{rpm}$, at which the inlet velocity was $0.25 \mathrm{~m} / \mathrm{s}$, the maximum predicted velocities in the lab-scale ORP were $0.43,0.48,0.86$ and $0.82 \mathrm{~m} / \mathrm{s}$ at simulation times of $5,7.5,10$, and $15 \mathrm{~s}$, respectively. Therefore, there was no significant change in the maximum velocity when the simulation time was higher than $10 \mathrm{~s}$. Figure 6 shows a quantitative comparison between the experimental data and numerical results obtained using the moving zone and inlet velocity for the paddle wheel. As observed from Figure 6, the three-dimensional fluid velocities in the $x$ and $y$ directions $\left(v_{x}\right.$ and $\left.v_{y}\right)$ predicted by the CFD model agreed well with experimental values. The slight differences observed for some points might be caused by nonstationary vortexes during the experiments.

Figure 7 shows the overall comparison between the predicted and measured velocities. The predicted velocities for the simulations using the moving zone boundary for the paddle wheel were determined as the average values obtained for $20 \mathrm{~s}$ additional flow time at intervals of $0.25 \mathrm{~s}$ after the simula- 

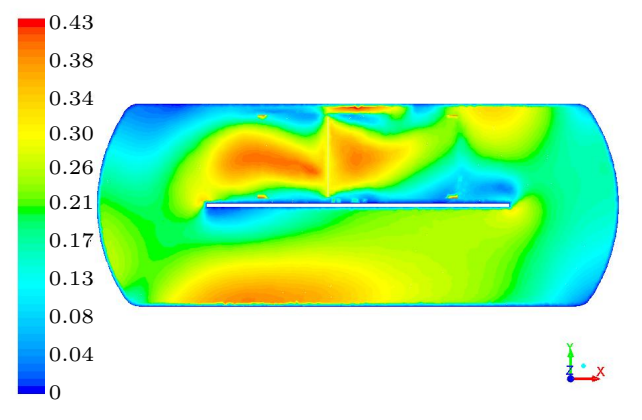

(a)

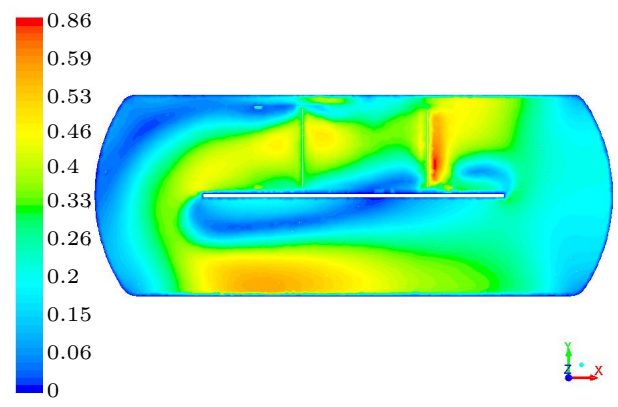

(c)

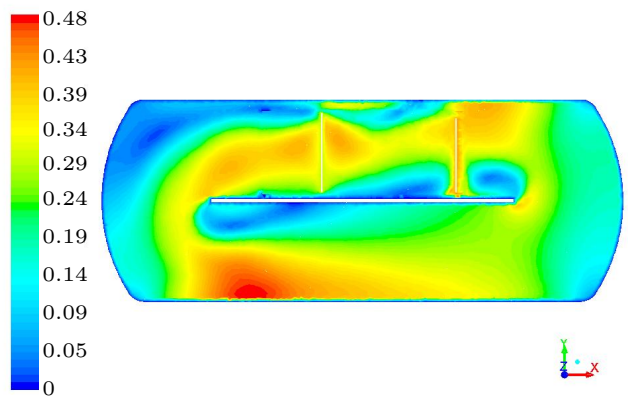

(b)

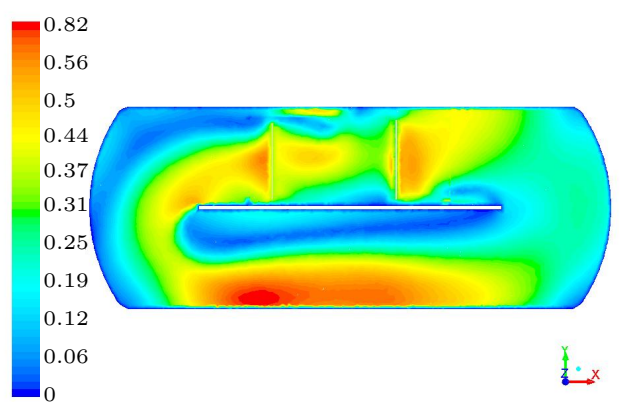

(d)

Figure 5: Predicted velocity profile distribution at a distance of $5 \mathrm{~cm}$ from the medium surface in the lab-scale ORP, at various flow times of (a) $5 \mathrm{~s}$, (b) $7.5 \mathrm{~s}$, (c) $10 \mathrm{~s}$, and (d) $15 \mathrm{~s}$

tion reached the pseudo-steady state. The $R^{2}$ value between the measured and predicted velocities by the CFD model with moving zone boundary for the paddle wheel was 0.9947 . The velocities for the simulations using the inlet velocity for the paddle wheel were determined by the CFD model at a steady-state condition. The $R^{2}$ value between the measured and predicted velocities by the CFD model with the velocity inlet boundary for the paddle wheel was 0.9838 . The simulation without considering the paddle wheel 


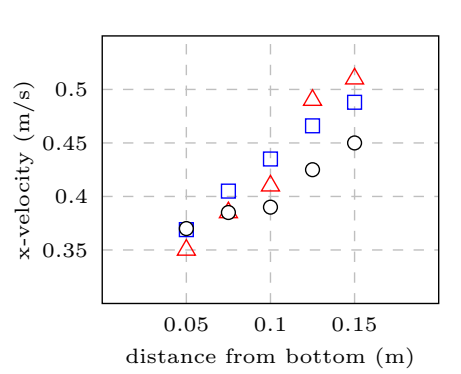

(a) x-velocity at position A

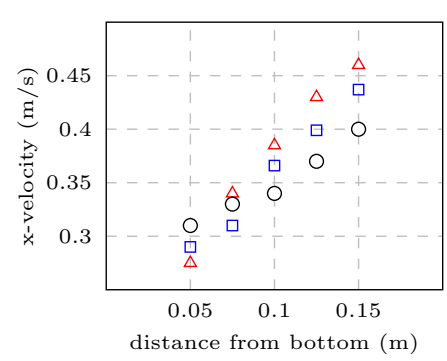

(d) x-velocity at position B

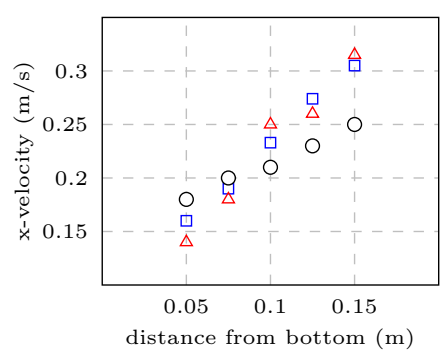

(g) x-velocity at position C

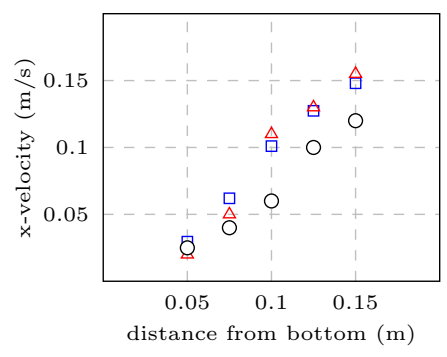

(j) $x$-velocity at position D

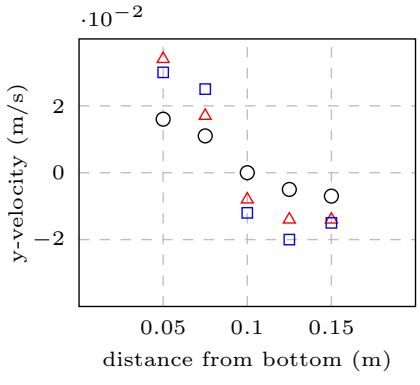

(b) y-velocity at position A

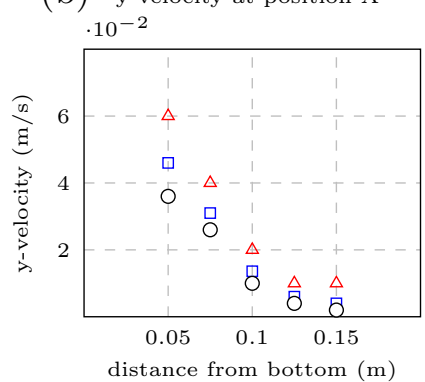

(e) y-velocity at position B

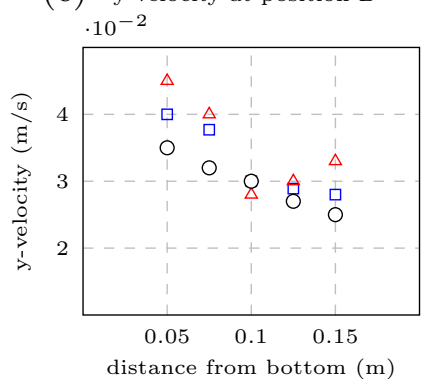

(h) y-velocity at position C

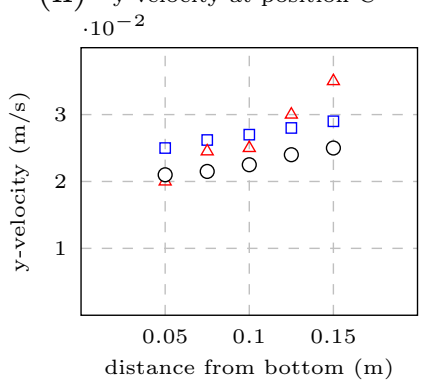

(k) y-velocity at position D

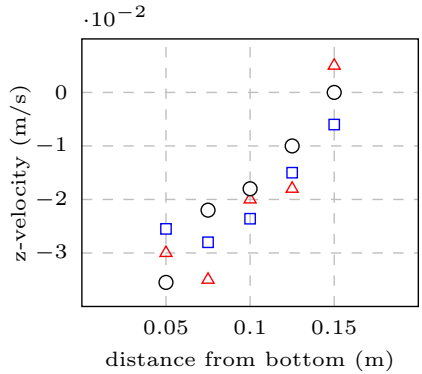

(c) z-velocity at position A

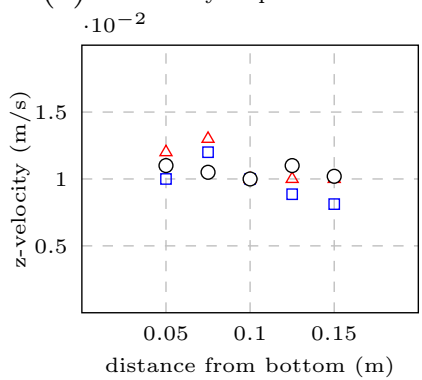

(f) z-velocity at position B

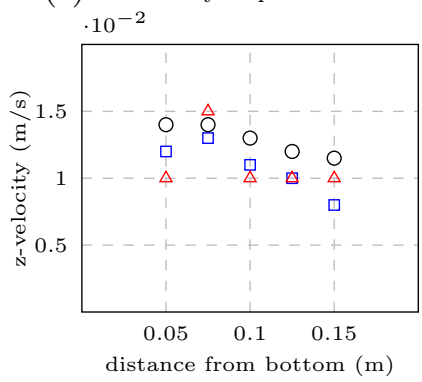

(i) z-velocity at position $\mathrm{C}$

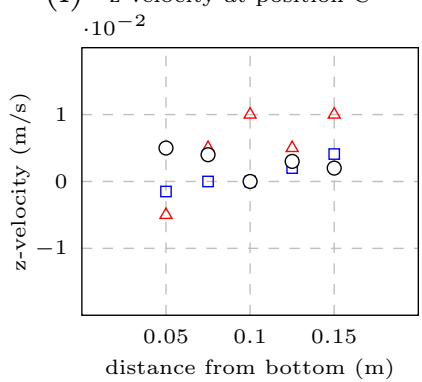

(1) z-velocity at position D

$\square$ CFD with moving zone boundary; $\triangle$ Experimental; O CFD velocity inlet boundary

Figure 6: Comparison of the predicted and measured three-dimensional velocities at various depths, with various distances from the outer wall of the open pond's channel 


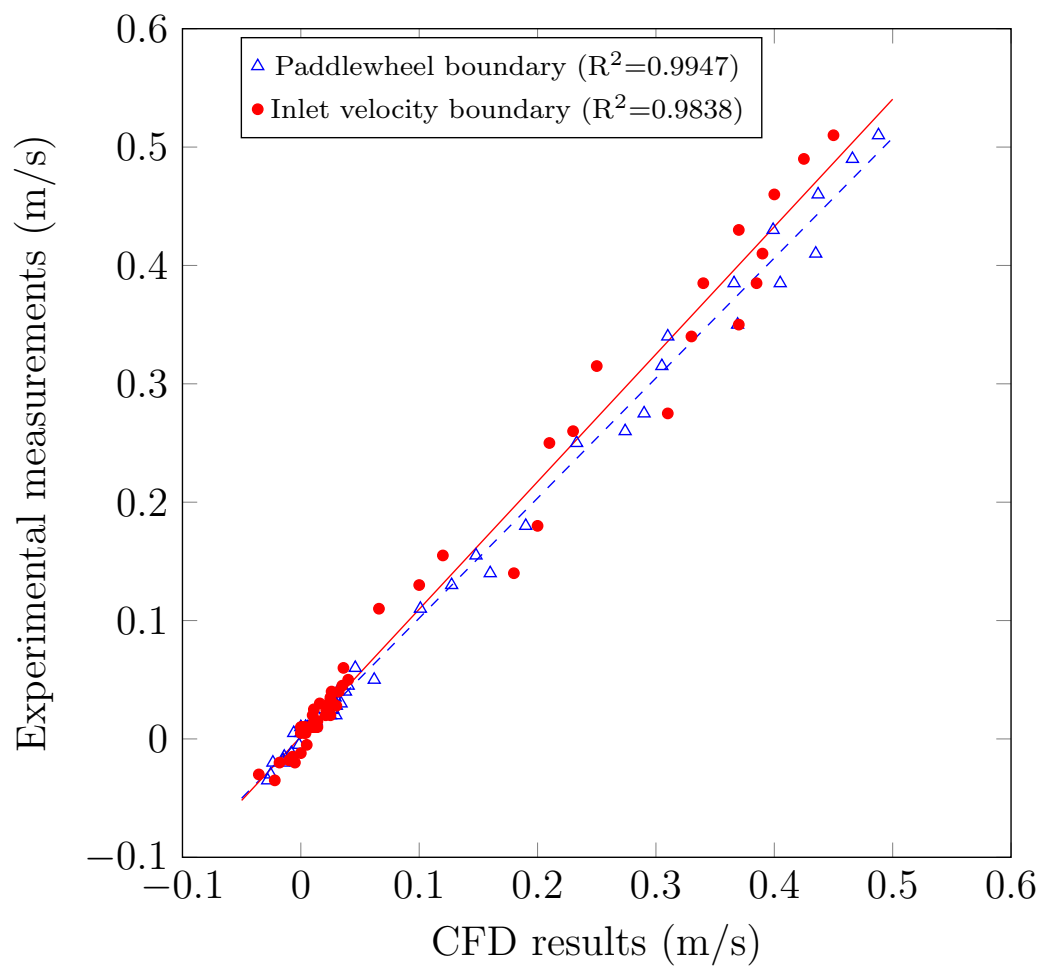

Figure 7: Statistical comparison of velocities obtained by experimental measurements, and CFD simulations with two types of boundary conditions for the paddle wheel

eliminated the effects of wave formation near the paddle wheel area. It can be observed from Figure 7 that there is a slight difference in the predicted velocity profiles using the two different types of boundaries for the paddle wheel. To reduce the computational time, the paddle wheel geometry was replaced with velocity inlet and outflow boundary conditions for simulating large-scale ORPs, as the simulation of the paddle wheel was not the focus of this study. Three different velocities, i.e., $0.1,0.2$, and $0.3 \mathrm{~m} / \mathrm{s}$ were consid- 


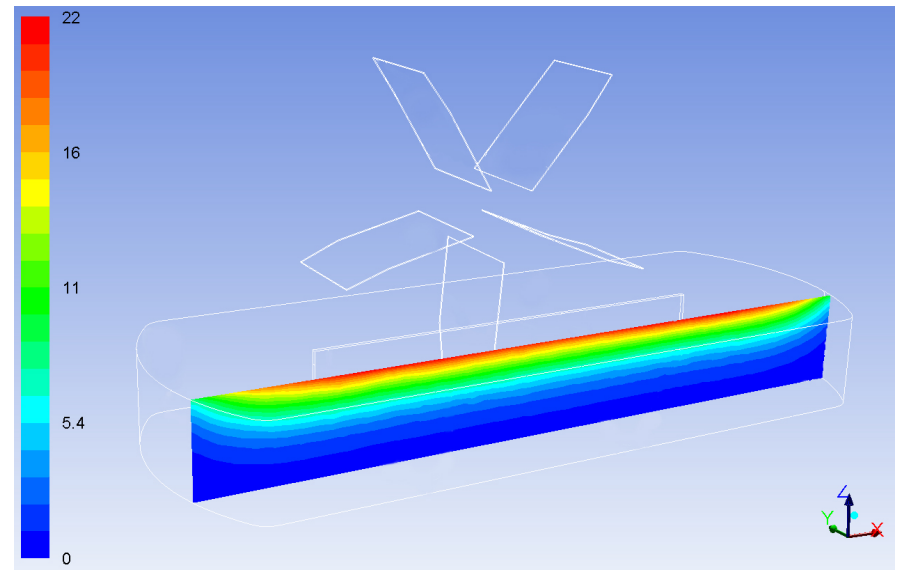

Figure 8: Contours of the predicted light intensity distribution in the lab-scale ORP channel containing the $C$. vulgaris culture medium with a dry algal concentration of $0.1 \mathrm{~g} / \mathrm{L}$

ered in this study. However, the simulation of paddle wheel design should be considered for the energy consumption analysis and the design of a paddle wheel.

\subsubsection{Light intensity validation}

Figure 8 shows the contour plot of the computed total radiative flux in the lab-scale ORP channel containing $C$. vulgaris culture medium at an initial cell concentration of $0.1 \mathrm{~g} / \mathrm{L}$. The predicted light intensity was higher in the regions far from the side walls and in the middle of the ORP channel. The low light intensity in the regions near the side walls, middle wall, and paddle wheel, was caused by the shielding of irradiation from the light panels at the top. 
Figure 9 shows the comparison between the measured and predicted total

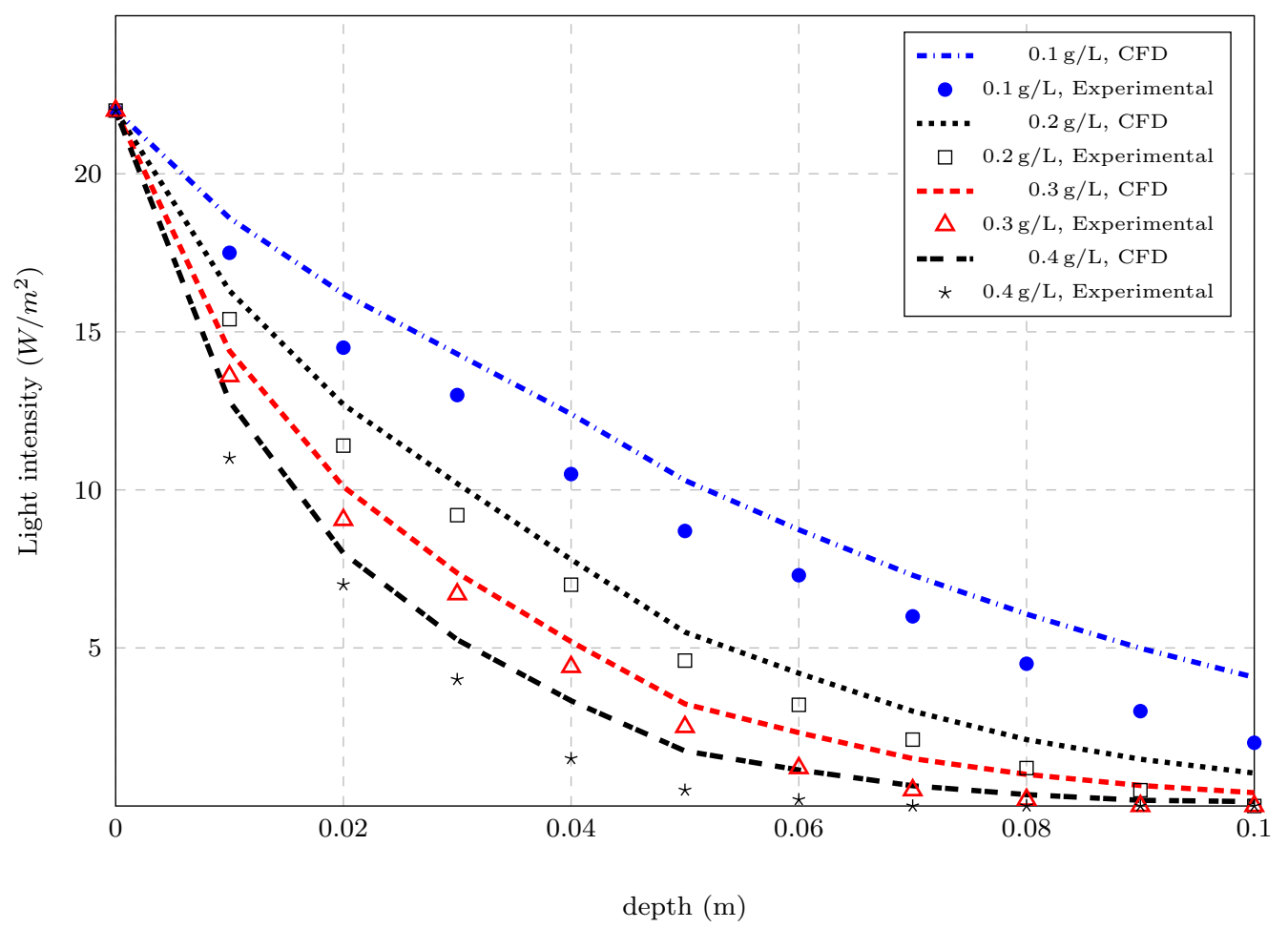

Figure 9: Comparison of experimental (symbols) and predicted (dash dotted lines) light distribution (400-700 nm) at various depths of the lab-scale ORP and concentrations of $0.1 \mathrm{~g} / \mathrm{L}, 0.2 \mathrm{~g} / \mathrm{L}, 0.3 \mathrm{~g} / \mathrm{L}$, and $0.4 \mathrm{~g} / \mathrm{L}$

radiative flux on a plane located in the middle of the lab-scale ORP channel

at various depths ranging from 0.01 to $0.10 \mathrm{~m}$ at various algal biomass concentrations of $0.1,0.2,0.3$, and $0.4 \mathrm{~g} / \mathrm{L}$. The predicted light intensity profiles were in good agreement with the measured profiles. The CFD model slightly overestimated the light intensity compared to the measured light intensity, which might be caused by shading effects during measurements. Figure 10 


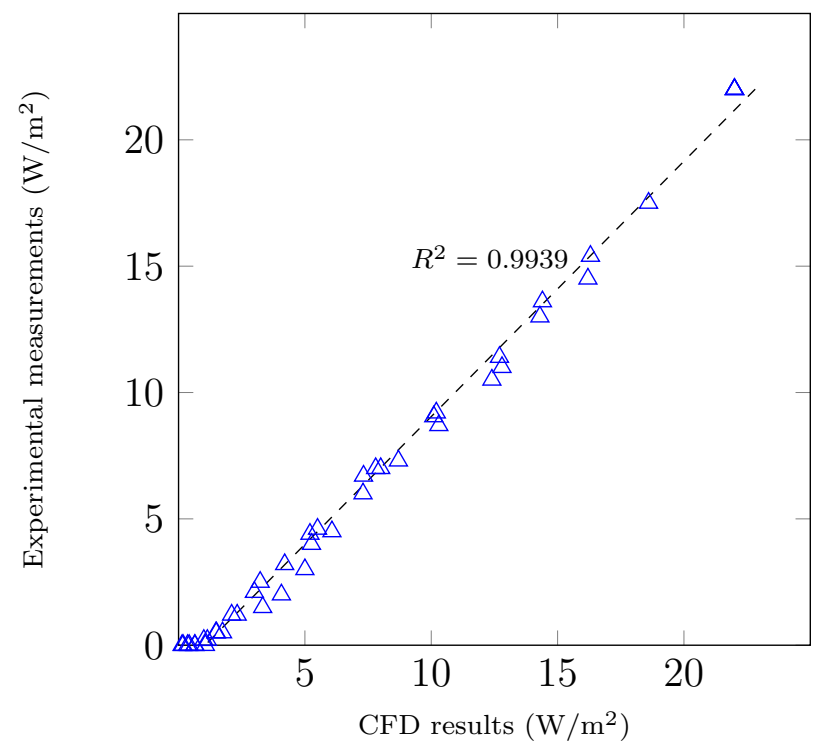

Figure 10: Statistical comparison of light intensities obtained by experimental measurements and CFD simulations at four different culture medium concentrations

shows the overall comparison between the predicted and measured light intensities. The $R^{2}$ value between the measured light intensities and predicted values by the CFD model was 0.9939. It can be observed from Figure 9 that the light intensity significantly decreased with increase of algal cell concentration. The measured light intensity at the depth of $0.05 \mathrm{~m}$ from the medium surface decreased from 8.7 to $0.5 \mathrm{~W} / \mathrm{m}^{2}$ when the algal cell concentration increased from 0.1 to $0.4 \mathrm{~g} / \mathrm{L}$. 
4.2. Effects of inlet velocity from paddle wheel and medium depth on mixing

\subsubsection{Effects of paddle wheel velocity}

The effects of inlet velocity and medium depth were studied on algal cell mixing in an ORP with $100 \mathrm{~m}^{2}$ footprint area and an algal cell concentration of $0.4 \mathrm{~g} / \mathrm{L}$. Figure 11 shows the velocity contours at the depth of $0.05 \mathrm{~m}$ from the medium surface for both medium depths of 0.2 and $0.3 \mathrm{~m}$. At the same inlet velocity, there is a slight difference in the velocity profiles at different medium depths as shown in Figures 11a vs. 11b, 11c vs. 11d, and 11e vs. 11f. At the depth of $0.05 \mathrm{~m}$ from the medium surface, the maximum velocity was $0.25 \mathrm{~m} / \mathrm{s}$ for the total medium depth of $0.2 \mathrm{~m}$, compared to $0.24 \mathrm{~m} / \mathrm{s}$ for the medium depth of $0.3 \mathrm{~m}$ when the inlet velocity from the paddle wheel was $0.1 \mathrm{~m} / \mathrm{s}$. When the inlet velocity was increased to 0.2 and $0.3 \mathrm{~m} / \mathrm{s}$, the maximum velocities increased to 0.46 and $0.69 \mathrm{~m} / \mathrm{s}$ at $0.2 \mathrm{~m}$ depth compared to 0.45 and $0.68 \mathrm{~m} / \mathrm{s}$ at $0.3 \mathrm{~m}$ medium depth, respectively. Although it was reported that the increase of the medium depth decreased the head loss per unit volume of the medium [22], the medium depth had no significant influence on the velocity distribution at the same distance from the channel free surface. The maximum velocities obtained for the inlet flow velocities of $0.1,0.2$, and $0.3 \mathrm{~m} / \mathrm{s}$ at the depth of $0.05 \mathrm{~m}$ from the medium surface 


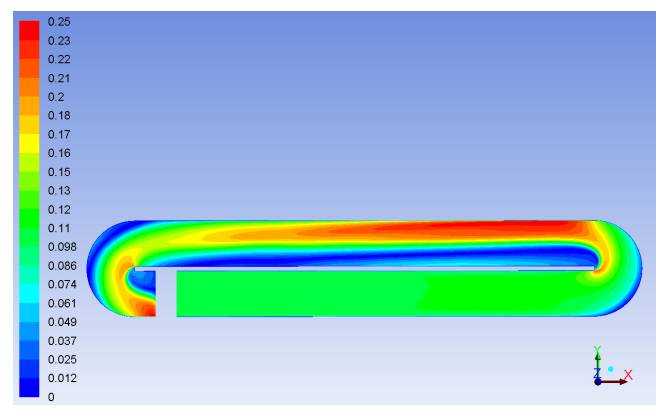

(a) $0.2 \mathrm{~m}$ channel depth- $0.1 \mathrm{~m} / \mathrm{s}$ inlet velocity

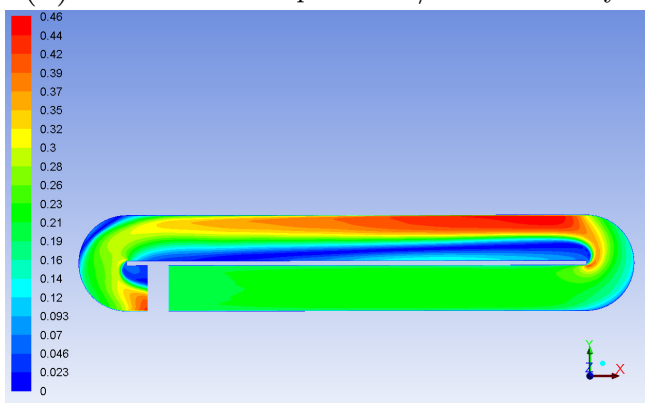

(c) $0.2 \mathrm{~m}$ channel depth- $0.2 \mathrm{~m} / \mathrm{s}$ inlet velocity

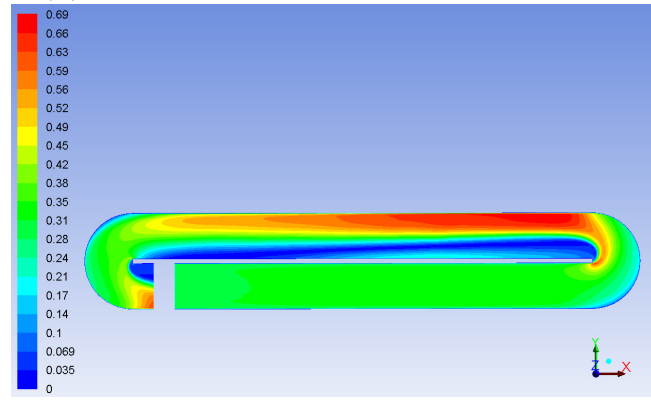

(e) $0.2 \mathrm{~m}$ channel depth- $0.3 \mathrm{~m} / \mathrm{s}$ inlet velocity

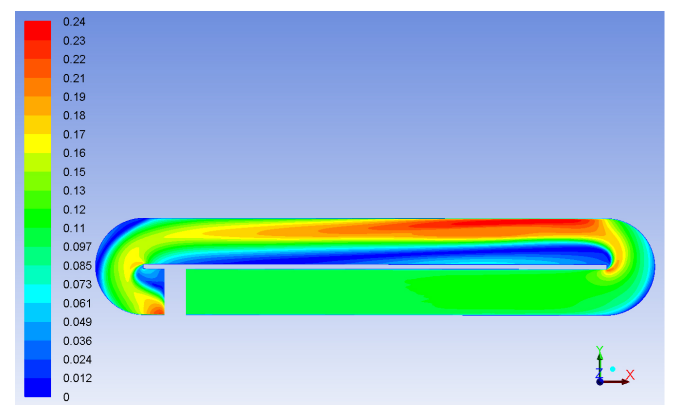

(b) $0.3 \mathrm{~m}$ channel depth- $0.1 \mathrm{~m} / \mathrm{s}$ inlet velocity

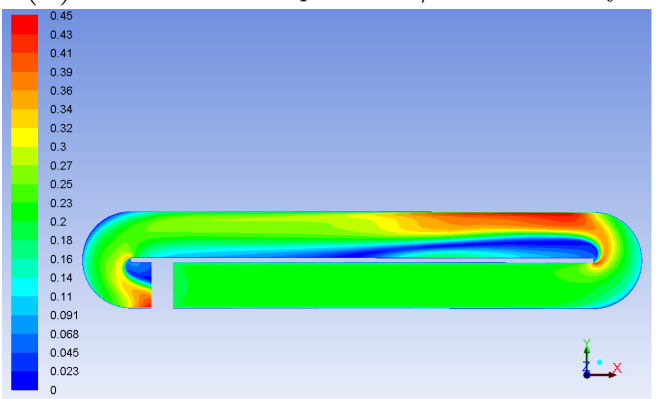

(d) $0.3 \mathrm{~m}$ channel depth- $0.2 \mathrm{~m} / \mathrm{s}$ inlet velocity

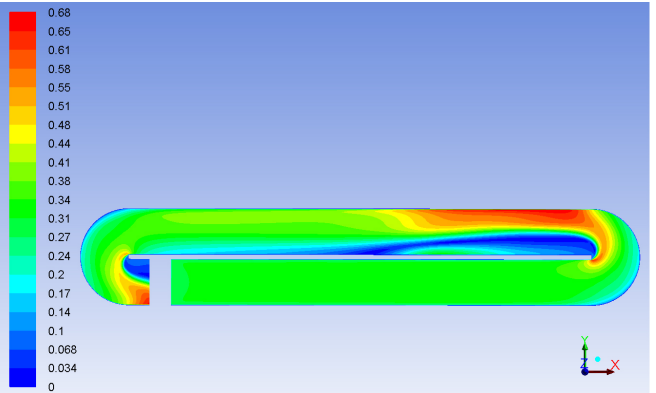

(f) $0.3 \mathrm{~m}$ channel depth- $0.3 \mathrm{~m} / \mathrm{s}$ inlet velocity

Figure 11: Contour plots of predicted velocity distribution at a depth of $0.05 \mathrm{~m}$ for the $100 \mathrm{~m}^{2}$ ORP operated at various inlet velocities and medium depths with an algal cell concentration of $0.4 \mathrm{~g} / \mathrm{L}$ 
were $0.25,0.45$, and $0.7 \mathrm{~m} / \mathrm{s}$, respectively, for both medium depths of 0.2 and $0.3 \mathrm{~m}$

The regions where the fluid velocity is lower than $0.1 \mathrm{~m} / \mathrm{s}$ were characterized as dead zones in the literature [8], where cells tend to settle. As observed from Figure 11, the dead zones mostly occur after the first bend, where the majority of head losses are located as well [8]. Although the increase of the inlet flow velocity from 0.2 to $0.3 \mathrm{~m} / \mathrm{s}$, increased the maximum velocity from 0.45 to $0.7 \mathrm{~m} / \mathrm{s}$ for both total medium depths of 0.2 and $0.3 \mathrm{~m}$, it did not significantly decrease the dead zone size. Hugan et al. [8] reported as well that the increase of the paddle wheel rotational speed from 12 to $20 \mathrm{rpm}$ (corresponding to a an average fluid velocity of 0.27 to $0.43 \mathrm{~m} / \mathrm{s}$ ) had little effect on dead zone volumes.

According to the literature [22], a velocity of $0.05 \mathrm{~m} / \mathrm{s}$ is sufficient to maintain the suspension of algal culture in a raceway culture. However, such a low velocity is difficult to maintain in a large pond because of frictional losses in the channel and corners. Figure 12 shows the cell concentration distribution in the ORP with medium depths of 0.2 and $0.3 \mathrm{~m}$ and an average cell concentration of $0.4 \mathrm{~g} / \mathrm{L}$ at various inlet velocities. These values were calculated by dividing the volume of a zone with a specific cell concentration 


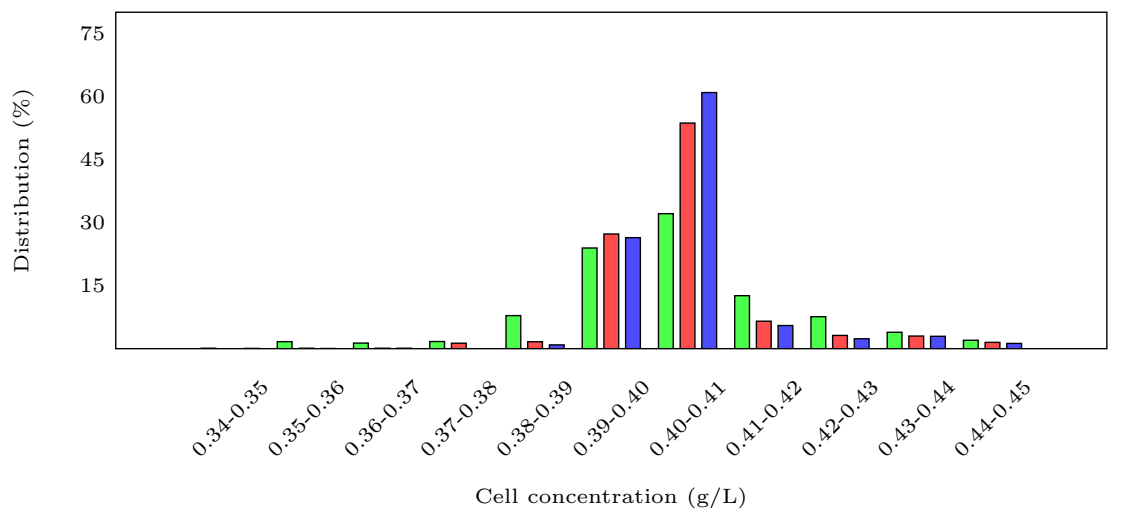

$\square 0.1 \mathrm{~m} / \mathrm{s}$ inlet velocity $\square 0.2 \mathrm{~m} / \mathrm{s}$ inlet velocity $\square 0.3 \mathrm{~m} / \mathrm{s}$ inlet velocity

(a) medium depth of $0.2 \mathrm{~m}$

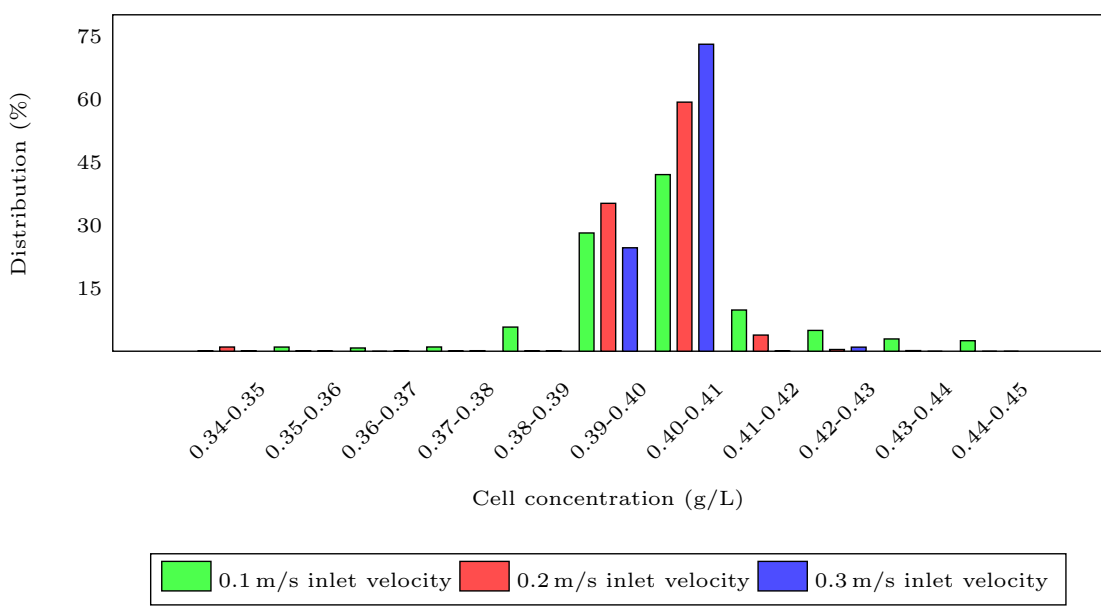

(b) medium depth of $0.3 \mathrm{~m}$

Figure 12: Cell concentration distribution in the $100 \mathrm{~m}^{2}$ ORP operated at various inlet velocities and microalgae medium depths of $0.2 \mathrm{~m}$ and $0.3 \mathrm{~m}$ and average cell concentration of $0.4 \mathrm{~g} / \mathrm{L}$ 
by the total volume of the medium. The values for the zones with cell concentrations higher than $0.45 \mathrm{~g} / \mathrm{L}$ and lower than $0.34 \mathrm{~g} / \mathrm{L}$ were not reported because they were negligible. As observed from Figures $12 \mathrm{a}$ and $12 \mathrm{~b}$, the increase of the inlet flow velocity from 0.1 to $0.3 \mathrm{~m} / \mathrm{s}$ increased the volume of the regions with average cell concentrations of approximately $0.4 \mathrm{~g} / \mathrm{L}$, resulting in a more uniform cell concentration profile. The increase of the inlet velocity from 0.1 to $0.2 \mathrm{~m} / \mathrm{s}$ increased the volumes of the region with a cell concentration between 0.39 and $0.41 \mathrm{~g} / \mathrm{L}$ from $68.6 \%$ to $87.45 \%$ for the total medium depth of $0.2 \mathrm{~m}$ and from $79.9 \%$ to $98.2 \%$ for the total medium depth of $0.3 \mathrm{~m}$. However, when the inlet velocity was further increased from 0.2 to $0.3 \mathrm{~m} / \mathrm{s}$, there was only a slight increase in the volume of the region with a cell concentration between 0.39 and $0.41 \mathrm{~g} / \mathrm{L}$, which was increased to $92.8 \%$ and $98.8 \%$ for the 0.2 and $0.3 \mathrm{~m}$ medium depths, respectively. When the inlet velocity increased from 0.1 to $0.3 \mathrm{~m} / \mathrm{s}$, the volume of the regions with a cell concentration of more than $0.41 \mathrm{~g} / \mathrm{L}$ decreased from $15.5 \%$ to $9 \%$ for the medium depth of $0.2 \mathrm{~m}$, and from $10.4 \%$ to $1 \%$ for the medium depth of $0.3 \mathrm{~m}$. The volume of the regions with a concentration of less than $0.39 \mathrm{~g} / \mathrm{L}$ decreased from $12.6 \%$ to $1.1 \%$ for the medium depth of $0.2 \mathrm{~m}$, and from $8.6 \%$ to $0.4 \%$ for the medium depth of $0.3 \mathrm{~m}$. However, the energy consumption 
415

416

417

418

419

420

421

422

423

424

425

426

427

428

429 430

by the paddle wheel increased as well with the increase of the inlet velocity.

\subsubsection{Effects of medium depth}

Figure 13 shows the effects of microalgal medium depth on the cell distribution along the ORP channels. By comparing the cell distribution contours for depths of 0.2 and $0.3 \mathrm{~m}$, it can be observed that the sedimentation of cells more likely occurs at the bottom of the ORP with a total medium depth of $0.2 \mathrm{~m}$; than at $0.3 \mathrm{~m}$ medium depth at the same inlet velocity. As observed from Figure 13, an increase in the medium depth from 0.2 to $0.3 \mathrm{~m}$ decreased the volume of the region with a cell concentration above $0.41 \mathrm{~g} / \mathrm{L}$ from $15.5 \%$ to $10.4 \%, 8.4 \%$ to $1.56 \%$, and $6.5 \%$ to $1 \%$ for velocities of 0.1 , 0.2 , and $0.3 \mathrm{~m} / \mathrm{s}$, respectively. An increase in the medium depth from 0.2 to $0.3 \mathrm{~m}$ decreased the volume of the region with a cell concentration lower than $0.39 \mathrm{~g} / \mathrm{L}$ from $12.6 \%$ to $1.1 \%, 3.1 \%$ to $1.1 \%$, and $1.2 \%$ to $0.4 \%$ for velocities of $0.1,0.2$, and $0.3 \mathrm{~m} / \mathrm{s}$, respectively. However, increasing the medium depth decreased the light penetration into the microalgal medium resulting in a lower specific growth rate. 


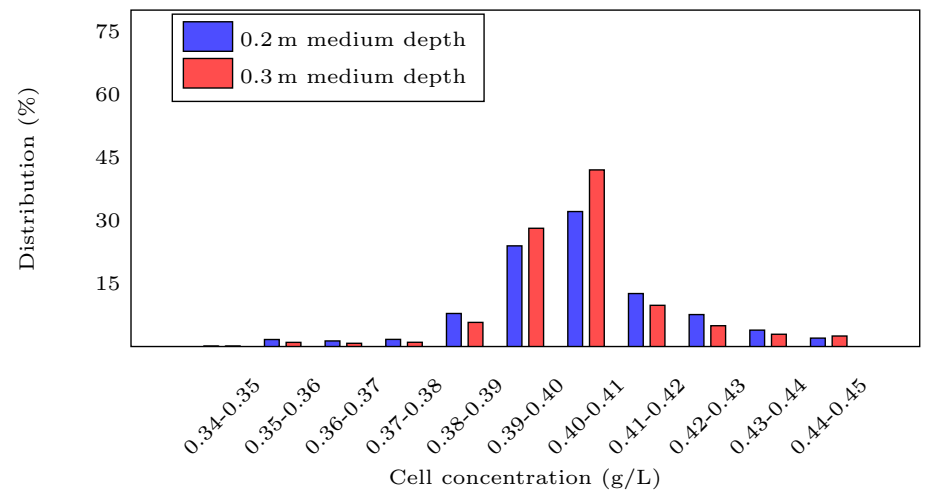

(a) $0.1 \mathrm{~m} / \mathrm{s}$ inlet velocity

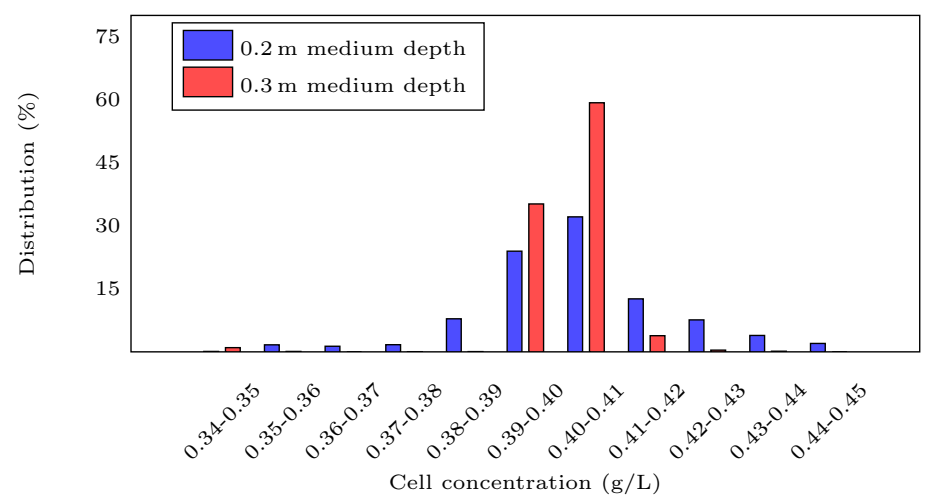

(b) $0.2 \mathrm{~m} / \mathrm{s}$ inlet velocity

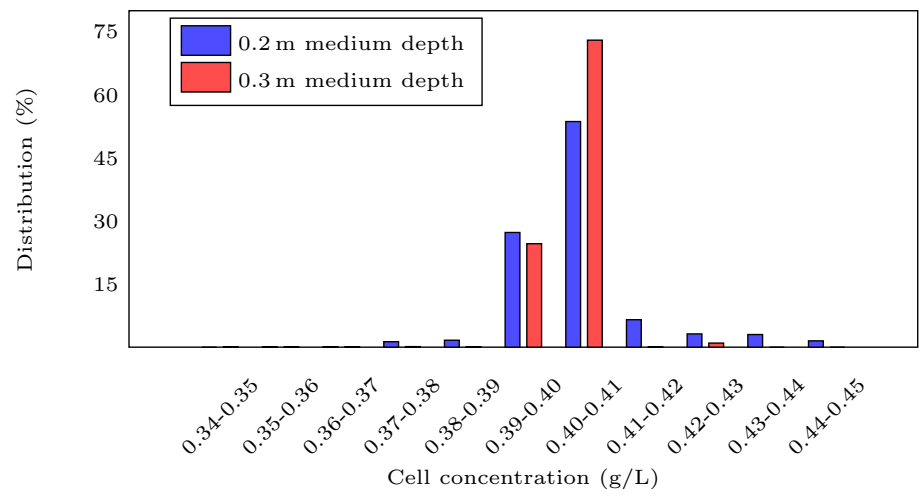

(c) $0.3 \mathrm{~m} / \mathrm{s}$ inlet velocity

Figure 13: Effects of the total medium depth on cell concentration distribution in ORP at various inlet velocities 


\subsection{Effects of local biomass concentration on light distribution profile}

The variation of local cell concentrations results in different optical characteristics in $C$. vulgaris culture medium. Figure 14 shows the local light intensity contours at the depth of $0.05 \mathrm{~m}$ for the ORPs with 0.2 and $0.3 \mathrm{~m}$ medium depths. There was a large variation of cell concentration in the ORP, which resulted in a large variation of local optical characteristics and light intensity along the channels. For the surface irradiance of $330 \mathrm{~W} / \mathrm{m}^{2}$, the maximum light intensity at the depth of $0.05 \mathrm{~m}$ did not change significantly when the inlet velocity increased from 0.1 to $0.3 \mathrm{~m} / \mathrm{s}$. However, it can be observed from the contour plots that the increase of the flow velocity resulted in more uniform light intensity distribution along the channels because of the more uniform cell distribution. The maximum light intensity of $165 \mathrm{~W} / \mathrm{m}^{2}$ at the depth of $0.05 \mathrm{~m}$ occurs after the first bend, where the local velocity was low, and thus the cell concentration was low as well. The increase of the inlet velocity from 0.1 to $0.3 \mathrm{~m} / \mathrm{s}$ resulted in a more uniform light intensity profile at the upper layers owing to improved mixing. The average light intensities at the depth of $0.05 \mathrm{~m}$ were 135,150 , and $148 \mathrm{~W} / \mathrm{m}^{2}$ for the ORP with a medium depth of $0.3 \mathrm{~m}$ for the inlet velocities of $0.1,0.2$, and $03 \mathrm{~m} / \mathrm{s}$, respectively. For the medium depth of $0.2 \mathrm{~m}$, the average light intensities at the 


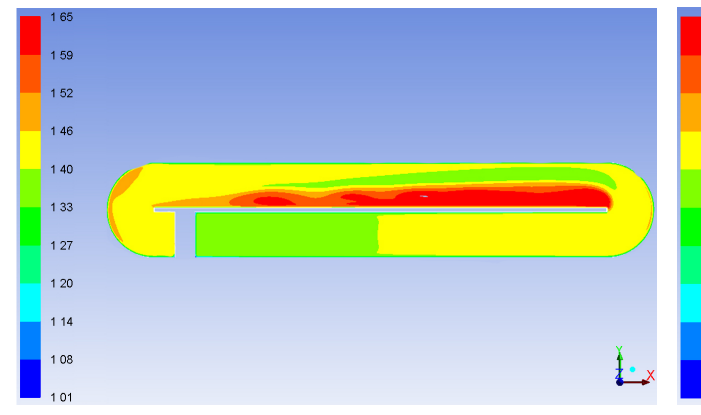

(a) $0.2 \mathrm{~m}$ depth- $0.1 \mathrm{~m} / \mathrm{s}$ inlet velocity

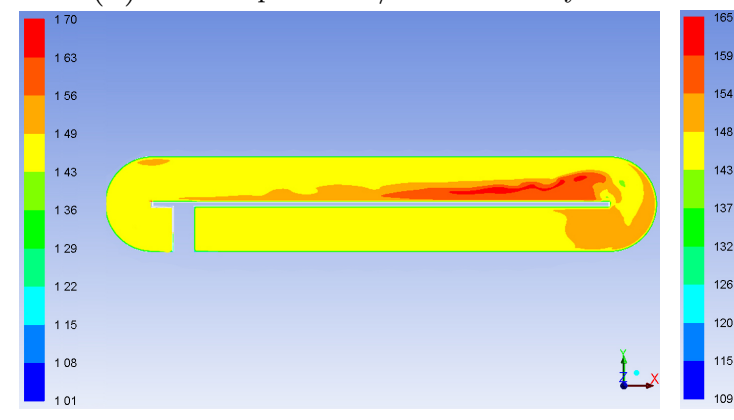

(c) $0.2 \mathrm{~m}$ depth- $0.2 \mathrm{~m} / \mathrm{s}$ inlet velocity

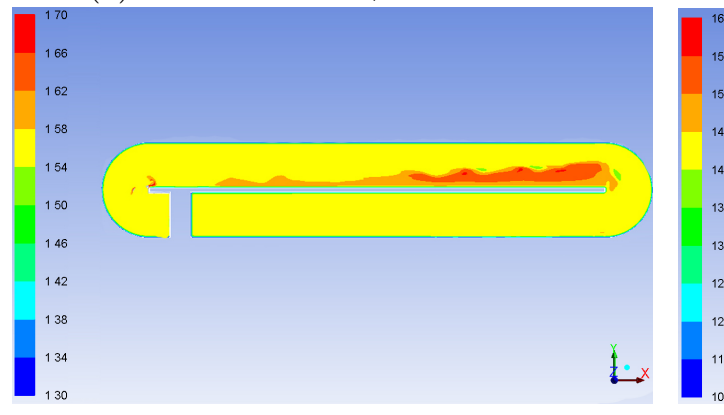

(e) $0.2 \mathrm{~m}$ depth- $0.3 \mathrm{~m} / \mathrm{s}$ inlet velocity

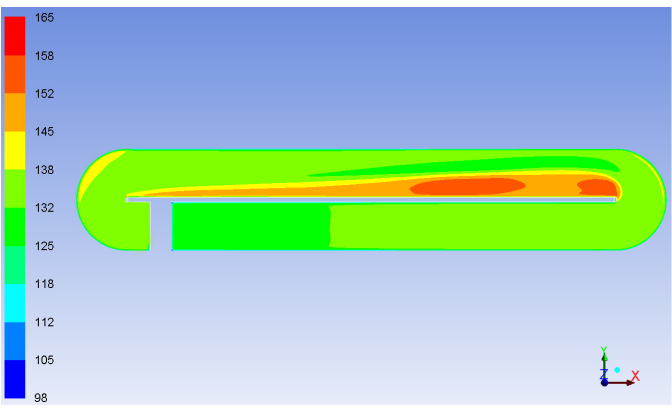

(b) $0.3 \mathrm{~m}$ depth- $0.1 \mathrm{~m} / \mathrm{s}$ inlet velocity

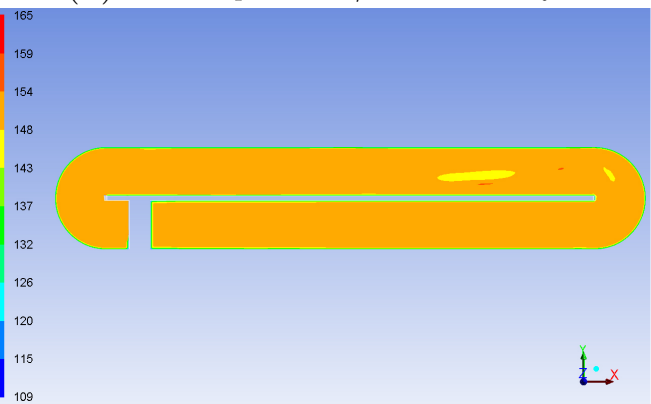

(d) $0.3 \mathrm{~m}$ depth- $0.2 \mathrm{~m} / \mathrm{s}$ inlet velocity

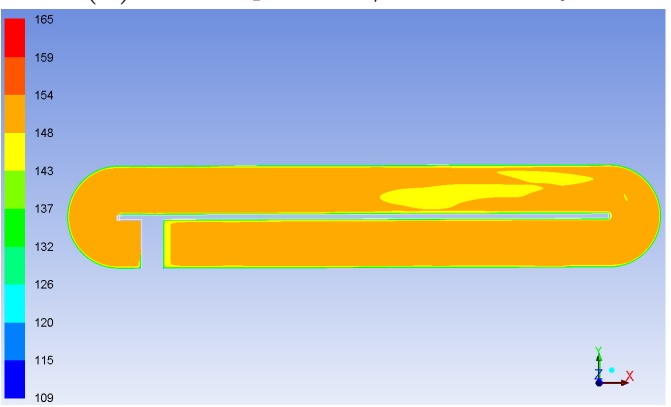

(f) $0.3 \mathrm{~m}$ depth- $0.3 \mathrm{~m} / \mathrm{s}$ inlet velocity

Figure 14: Predicted light intensity contours at depth of $0.05 \mathrm{~m}$ and various flow velocities for ORPs with 0.2 and $0.3 \mathrm{~m}$ medium depths 

change the average light intensity in the ORP.

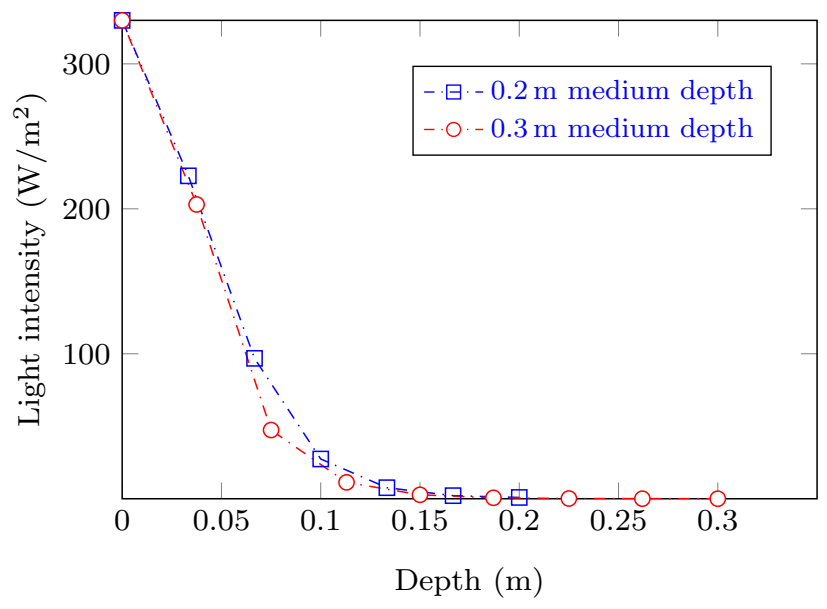

Figure 15: Predicted light penetration into the channel depth for ORPs with 0.2 and $0.3 \mathrm{~m}$ medium depths operated at $0.2 \mathrm{~m} / \mathrm{s}$ paddlewheel velocity, $0.4 \mathrm{~g} / \mathrm{L}$ average cell concentration, and $330 \mathrm{~W} / \mathrm{m}^{2}$ surface irradiance

453

454 and $0.3 \mathrm{~m} / \mathrm{s}$, respectively. Therefore, the increase of inlet velocity increased the uniformity of light intensity at a specific depth; it did not significantly

Figure 15 shows the light intensity distribution along the channel depth at the middle of the channel across the channel width for ponds with 0.2 and $0.3 \mathrm{~m}$ medium depths, at the typical paddle wheel velocity of $0.2 \mathrm{~m} / \mathrm{s}$ and $0.4 \mathrm{~g} / \mathrm{L}$ average cell concentration. The light intensity drastically dropped after a few centimeters from the surface of the channel. The maximum light intensity at the depth of $0.05 \mathrm{~m}$ decreased to $45 \%$ of the surface irradiance for $0.2 \mathrm{~m}$ medium depth and $41 \%$ for the $0.3 \mathrm{~m}$ medium depth. Therefore,

depth of $0.05 \mathrm{~m}$ were 143,148 , and $155 \mathrm{~W} / \mathrm{m}^{2}$ at inlet velocities of $0.1,0.2$, 
although at some areas of the channel optical parameters were higher because of the cell sedimentation, the light absorption by microalgal cells did not change because of the low light penetration into the medium. However, the cell sedimentation prevented the cells from receiving sufficient light energy, which resulted in lower biomass production rate.

\section{Conclusions}

An integrated three-dimensional CFD and spectral radiation model was developed to simulate the hydrodynamics and light transfer in ORPs with different algal cell concentrations and medium depths. The predicted threedimensional velocity and light intensity agreed well with the measured values collected on a lab-scale ORP. There was a slight difference in the predicted velocity profiles using two different types of boundaries, i.e., the moving zone boundary and inlet velocity boundary for the paddle wheel, with $R^{2}$ values between the predicted and measured velocities of 0.9947 and 0.9838 , respectively. The $R^{2}$ value between the predicted and measured light intensity was 0.9939 . Simulations showed that the increase of the paddle wheel velocity of a $100 \mathrm{~m}^{2}$ ORP increased the volume of the regions with an average cell concentration of approximately $0.4 \mathrm{~g} / \mathrm{L}$, resulting in a more uniform cell 
concentration profile. The increase of the inlet velocity from 0.1 to $0.2 \mathrm{~m} / \mathrm{s}$ increased the volumes of the region with a cell concentration between 0.39 and $0.41 \mathrm{~g} / \mathrm{L}$ from $68.8 \%$ to $87.45 \%$ and from $79.9 \%$ to $98.2 \%$ for the total medium depths of 0.2 and $0.3 \mathrm{~m}$, respectively. However, when the inlet velocity was further increased from 0.2 to $0.3 \mathrm{~m} / \mathrm{s}$, there was only a slight increase in the volume of the region with a cell concentration between 0.39 and $0.41 \mathrm{~g} / \mathrm{L}$, which was increased to $92.8 \%$ and $98.8 \%$ for the 0.2 and $0.3 \mathrm{~m}$ medium depths, respectively. In addition, the simulation results showed that the sedimentation of cells more likely occurred at the bottom of the ORP with a total medium depth of $0.2 \mathrm{~m}$ than at $0.3 \mathrm{~m}$ medium depth at the same inlet velocity. The increase of the inlet velocity from the paddle wheel resulted in a uniformly distributed light intensity in the region near the medium surface. However, as the light intensity dropped sharply after a few centimeters from the surface of the medium, the sedimentation that occurred at the bottom of the ORPs had negligible effects on the light penetration depth in the medium. 


\section{Acknowledgments}

A contribution of North Carolina Agricultural and Technical State University, supported by funds fully provided by U.S. Department of Agriculture (USDA NIFA awards: 2013-38821-21141 and NC.X-294-5-15-130-1). Mention of a trade name, proprietary products, or company name is for presentation clarity and does not imply endorsement by the authors or the university.

\section{References}

[1] P. Hartmann, D. Demory, C. Combe, R. Hamouda, A.-C. Boulanger, M.-O. Bristeau, J. Sainte-Marie, B. Sialve, J.-P. Steyer, S. Rabouille, et al., "Growth rate estimation of algae in raceway ponds: A novel approach," in The 19th World Congress of the International Federation of Automatic Control, 2014.

[2] A. Mehrabadi, R. Craggs, and M. Farid, "Wastewater treatment high rate algal ponds (wwt hrap) for low-cost biofuel production," Bioresource technology, 2014.

[3] M. Prussi, M. Buffi, D. Casini, D. Chiaramonti, F. Martelli, M. Carnevale, M. R. Tredici, and L. Rodolfi, "Experimental and nu- 
merical investigations of mixing in raceway ponds for algae cultivation," Biomass and Bioenergy, vol. 67, pp. 390 - 400, 2014.

[4] H. Ali, T. A. Cheema, H.-S. Yoon, Y. Do, and C. W. Park, "Numerical prediction of algae cell mixing feature in raceway ponds using particle tracing methods," Biotechnology and bioengineering, vol. 112, no. 2, pp. 297-307, 2015.

[5] J. Cheng, Z. Yang, Q. Ye, J. Zhou, and K. Cen, "Enhanced flashing light effect with up-down chute baffles to improve microalgal growth in a raceway pond," Bioresource Technology, vol. 190, pp. 29 - 35, 2015.

[6] H. Delavari Amrei, R. Ranjbar, S. Rastegar, B. Nasernejad, and A. Nejadebrahim, "Using fluorescent material for enhancing microalgae growth rate in photobioreactors," Journal of Applied Phycology, vol. 27, no. 1, pp. 67-74, 2014.

[7] R. Pandey, A. Sahu, V. K. K, and P. M, "Studies on light intensity distribution inside an open pond photo-bioreactor," Bioprocess and Biosystems Engineering, vol. 38, no. 8, pp. 1547-1557, 2015.

[8] J. Huang, X. Qu, M. Wan, J. Ying, Y. Li, F. Zhu, J. Wang, G. Shen, J. Chen, and W. Li, "Investigation on the performance of raceway ponds 
with internal structures by the means of $\{\mathrm{CFD}\}$ simulations and experiments," Algal Research, vol. 10, pp. $64-71,2015$.

[9] Z. C. Wheaton and G. Krishnamoorthy, "Modeling radiative transfer in photobioreactors for algal growth," Computers and Electronics in Agriculture, vol. 87, pp. $64-73,2012$.

[10] S. Park and Y. Li, "Integration of biological kinetics and computational fluid dynamics to model the growth of Nannochloropsis salina in an open channel raceway," Biotechnology and bioengineering, 2015.

[11] K. Liffman, D. A. Paterson, P. Liovic, and P. Bandopadhayay, "Comparing the energy efficiency of different high rate algal raceway pond designs using computational fluid dynamics," Chemical Engineering Research and Design, vol. 91, no. 2, pp. 221 - 226, 2013.

[12] H. Hadiyanto, S. Elmore, T. V. Gerven, and A. Stankiewicz, "Hydrodynamic evaluations in high rate algae pond (hrap) design," Chemical Engineering Journal, vol. 217, no. 0, pp. 231 - 239, 2013.

[13] D. Chiaramonti, M. Prussi, D. Casini, M. R. Tredici, L. Rodolfi, N. Bassi, G. C. Zittelli, and P. Bondioli, "Review of energy balance in raceway ponds for microalgae cultivation: Re-thinking a traditional 
system is possible," Applied Energy, vol. 102, no. 0, pp. 101 - 111, 2013. Special Issue on Advances in sustainable biofuel production and use \{XIX $\}$ International Symposium on Alcohol Fuels - $\{$ ISAF $\}$.

[14] R. Hreiz, B. Sialve, J. Morchain, R. Escudi, J.-P. Steyer, and P. Guiraud, "Experimental and numerical investigation of hydrodynamics in raceway reactors used for algaculture," Chemical Engineering Journal, vol. 250, no. 0, pp. $230-239,2014$.

[15] J. Bitog, I.-B. Lee, C.-G. Lee, K.-S. Kim, H.-S. Hwang, S.-W. Hong, I.-H. Seo, K.-S. Kwon, and E. Mostafa, "Application of computational fluid dynamics for modeling and designing photobioreactors for microalgae production: A review," Computers and Electronics in Agriculture, vol. 76, no. 2, pp. $131-147,2011$.

[16] V. Pareek, S. Chong, M. Tadé, and A. A. Adesina, "Light intensity distribution in heterogenous photocatalytic reactors," Asia-Pacific Journal of Chemical Engineering, vol. 3, no. 2, pp. 171-201, 2008.

[17] N. Almohammed, F. Alobaid, M. Breuer, and B. Epple, "A comparative study on the influence of the gas flow rate on the hydrodynamics of a 
gassolid spouted fluidized bed using eulereuler and eulerlagrange/dem models," Powder Technology, vol. 264, no. 0, pp. 343 - 364, 2014.

[18] S. Hadjoudja, V. Deluchat, and M. Baudu, "Cell surface characterisation of microcystis aeruginosa and chlorella vulgaris," Journal of colloid and interface science, vol. 342, no. 2, pp. 293-299, 2010.

[19] H. Berberoglu, P. S. Gomez, and L. Pilon, "Radiation characteristics of botryococcus braunii, chlorococcum littorale, and chlorella sp. used for fixation and biofuel production," Journal of Quantitative Spectroscopy and Radiative Transfer, vol. 110, no. 17, pp. 1879 - 1893, 2009.

[20] B. Kong and R. D. Vigil, "Simulation of photosynthetically active radiation distribution in algal photobioreactors using a multidimensional spectral radiation model," Bioresource technology, vol. 158, pp. 141-148, 2014 .

[21] K. Hannis, Optical behavior of algae particles in photobioreactors. $\mathrm{PhD}$ thesis, TU Delft, Delft University of Technology, 2013.

[22] R. A. Andersen, Algal culturing techniques. Academic press, 2005. 